\section{BIOCHEMICAL AND CLINICAL ANALYSIS}

Luminescence fiber-optic biosensor. L.J. Blum, S.M. Gautier and P.R. Coulet.

Verff. beschreiben den Aufbau und die Leistungsfähigkeit eines neuen Biosensor-Typs, der mit immobilisierten Bioluminescenz-Enzymen arbeitet und mit einer Faseroptiksonde ausgestattet ist. Die Enyzme werden an vorher aktivierten Nylonmembranen immobilisiert und die Membranen in engen Kontakt mit der Spitze eines Bündels von optischen Glasfasern gebracht (Schemaskizze im Original). Der Sensor wird in eine thermostisierte, mit einer Rührvorrichtung versehene und durch eine PVC-Hülle vor Licht geschützte Zelle eingetaucht. Das Licht der bei den analytischen Reaktionen induzierten Luminescenz wird durch die Glasfaserbündel in die Photomultiplierröhre eines Luminometers geleitet. Eine Reihe von Beispielen mit immobilisierter Glühwürmchen-Luciferase (und NADH-Messung) oder immobilisierter Meerrettich-Peroxidase (und Messung von $\mathrm{H}_{2} \mathrm{O}_{2}$ ) werden beschrieben. - Anal. Lett. 21, $717-726$ (1988). Lab. Génie Enzymat., Atel. Biotechnol., Univ. Lyon I, Villeurbanne (F)

W. Czysz

Semiconductor laser fluorimetry for enzyme and enzymatic assays. T. Imasaka, T. Okazaki and N. Ishibashi.

Zur Bestimmung von Xanthin und Xanthin-Oxidase wenden die Verff. ein Verfaren der Halbleiter-Laser-Fluorimetrie im nahen Infrarot an, dessen Grundlagen an anderer Stelle (K. Sauda, T. Imasaka and N. Ishibashi: Anal. Chem. 58, 2649 (1986)) beschrieben wurden. Die Anregung erfolgt durch einen Halbleiter-Laser bei $780 \mathrm{~nm}$. Grundlage des Verfahrens ist die Beobachtung, da $B$ die Fluorescenz von Indocyaningrün im NIR-Bereich durch $\mathrm{H}_{2} \mathrm{O}_{2}$ unterdrückt wird. Das für diese Reaktion erforderliche $\mathrm{H}_{2} \mathrm{O}_{2}$ erzeugt man durch Umwandlung von Xanthin durch Xanthin-Oxidase zu Harnsäure (Xanthin $+\mathrm{O}_{2} \rightarrow$ (XanthinOxidase) $\rightarrow$ Harnsäure $+\mathrm{H}_{2} \mathrm{O}_{2}$ ). Die Abnahme der Fluorescenzintensität kann je nach Versuchsanlage zur Bestimmung von Xanthin oder Xanthin-Oxidase benutzt werden. Für Xanthin erhält man eine lineare Eichgerade im Bereich $5 \times 10^{-5}-5 \times 10^{-7} \mathrm{M}$. - Anal. Chim. Acta 208, $325-329$ (1988). Fac. Engin., Kyushu Univ., Hakozaki, Fukuoka (J)

W. Czysz

Di-isopropyl fluorophosphate electrode based on squid nerve tissue. S. Uchiyama, Y. Sato, Y. Tofuko and S. Suzuki.

Di-isopropylfluorophosphat spielt in physiologischen Abläufen im Nervengewebe speziell von Tintenfischen eine Rolle. Es ist bekannt, daß die Verbindung durch die ebenfalls in diesen Geweben enthaltene Diisopropylfluorophosphatase unter Abspaltung von Fluorid hydrolysiert wird (Reaktionsformeln im Original). Auf der Grundlage dieser Beobachtung wurde eine Fluorid-ionenselektive Elektrode mit einer zwischen zwei Dialysemembranen eingeschlossenen Schicht homogenisierten Tintenfischnervengewebes überzogen und die so hergestellte Di-isopropylfluorophosphat-sensitive Elektrode zur Bestimmung dieser Verbindung eingerichtet. Man arbeitet bei $\mathrm{pH} 7,1$ und $0^{\circ} \mathrm{C}$, um eine Zersetzung der Gewebesubstanz zu vermeiden. Die Meßzelle wird vor Gebrauch in einem TISAB-I (Orion) Citratpuffer pH 7,13 h konditioniert. Die Messungen werden in einem mikroprozessorgesteuerten Ionalyzer (Orion 901) ausgeführt. Die halblogarithmische Eichkurve ist im Bereich $2 \times 10^{-5}-7 \times 10^{-3} \mathrm{M}$ linear (RSD $<3 \%$ ). Die Steilheit der potentiometrischen Kurve beträgt $44 \mathrm{mV} /$ Dekade. Die Nachweisgrenze liegt bei $8 \times 10^{-6} \mathrm{M}$. Die Elektrodenkonstanz bleibt ca. 16 Tage erhalten. Anal. Chim. Acta 209, $351-355$ (1988). Dep. Environ. Engin., Inst. technol., Saitama (J)

W. Czysz

Enzyme-amplified receptor assay predictive model and analytical limits. S.F. Hallowell and G.A. Rechnitz.

Es wird eine theoretische Grundlage für enzymverstärkte RezeptorAssays (ERA) entwickelt und Kriterien für den allgemeinen Fall eines beliebigen Rezeptorsystems festgelegt. Ausgangspunkt dieser neuen Analysenmethode ist das Vorhandensein von biologischen Rezeptorsystemen, deren normale biologische Funktion durch Pharmaka oder Toxine vermittelt wird, und die mit ihnen noch in sehr geringen Konzentrationen reagieren. Dieses spezifische Erkennungsprinzip wird beim ERA benutzt (S.F. Hallowell and G.A. Rechnitz: Anal. Lett. 20. 1929 (1987); vgl. diese Z. 331, 788 (1988)). Die analytischen Kriterien zur Durchführung des Assays werden ermittelt: relevante Affinitätskonstanten, die Konzentrationen des enzymmarkierten Liganden und des Rezeptors. Entscheidend ist die Konkurrenzreaktion des freien Analyten mit dem enzymmarkierten Liganden für eine bestimmte Anzahl Rezeptor-Bindungsstellen im Vergleich zu einem bekannten Standard. - Anal. Lett. 21, 921 - 942 (1988). Dept. Chem. Biochem., State Univ., Newark., DE (USA)

W. Czysz

Microanalysis of urinary calculi by quantitative X-ray diffraction procedures. M.A.E. Wandt and A.L. Rodgers.

Ten urinary calculi were quantitatively analysed using two microanalytical X-ray diffraction techniques. The first employs a combination of separate diffraction and absorption measurements whereas the second uses silver peak attenuation to determine constituent concentrations. Both approaches show good agreement with each other and with results obtained independently by elemental analysis of the same specimens. - Analyst 113, $783-787$ (1988). Dept. Phys. Chem., Univ. Cape Town, Rondebosch (ZA)

The combination of the PIXE-PIGME techniques for the elemental analysis of biological samples. H. Fakhouri and N.A. Dyson.

PIXE-PIGME-Techniken werden zur gleichzeitigen Bestimmung von 14 Elementen in Placentagewebe verwendet. Die Messungen werden bei $2,5 \mathrm{meV}$ aufgenommen bei Verwendung von Stromstärken in der Größenordnung von $25 \mathrm{nA}$. Röntgen- und $\gamma$-Strahldaten werden gleichzeitig aufgenommen. Die absoluten Konzentrationen der Elemente können durch Vergleich mit Messungen von Eichstandards bestimmt werden. Hier werden die absoluten Konzentrationen von 14 Elementen in Gewebe in ppm Trockengewicht bestimmt. Die Ergebnisse zeigen eine Abhängigkeit der Menge an Ca mit dem Alter des Gewebes. - J. Trace Microprobe Techn. 6, 73-86 (1988). Phys. Dept., Univ. Birmingham (GB)

R.H.S

Measurement of femtogram quantities of trace elements using an X-ray microprobe. R.D. Giauque, A.C. Thompson, J.H. Underwood, Y. Wu K.W. Jones and M.L. Rivers

Femtogram quantities of trace elements in biological materials have been measured with an X-ray microprobe. The microprobe uses a pair of concave spherical mirrors which were coated with tungsten-carbon multilayers. Atranged in the Kirkpatrick-Baez geometry, the mirrors produce a focused and quasi-monochromated beam from the synchrotron white radiation beam. The beam spot size is less than $10 \times 10 \mu \mathrm{m}$ and the monochromated beam has a band-pass of $1 \mathrm{keV}$ at $10 \mathrm{keV}$. Minimum detectable limits achieved varied from 3 to $70 \mathrm{fg}$ for the elements $\mathrm{Zn}(Z=30)$ to $\mathrm{K}(Z=19)$. - Anal. Chem. 60, 855-858 (1988). Lawrence Berkeley Lab., Univ., Berkeley, CA (USA)

Feststoff-AAS mit Deuterium-Untergrundkompensation II. E. Lücker, E. Hornung, A. Rosopulo, G. Küllmer und C. Busche.

Neben der Bestimmung von Blei können auch andere Spurenelemente wie Cadmium, Mangan und Zink in verschiedenen biologischen Matrices mit Feststoff-AAS und „High-Energy“-Deuterium-Untergrundkompensation sehr gut erfaßt werden. Das von den Verff. in LP 10, 64 (1986) beschriebene Verfahren zur atomabsorptionsspektrometrischen Feststoffanalytik mittels $\mathrm{D}_{2}$-Untergrundkompensation wird hier für Matrices wie Leber, Nieren, Muskulatur und Milchpulver eingesetzt. Da die Eichung der Geräte auch mit flüssigen Bezugslösungen ohne Einschränkung möglich ist, ergibt sich eine Unabhängigkeit vom Konzentrationsbereich des Standard-Referenzmaterials und damit eine bessere Reproduzierbarkeit. Die Methode kann als Referenz- oder Screening-Verfahren alternativ zur Standardmethode in Routinelaboratorien eingesetzt werden. - LP-Special 88, 139-143 (1988). Inst. Tierärztl. Nahrungsmittelkunde, Justus-Liebig-Univ., D-6300 Gießen

R.H.S.

Investigation of metal-species ( $\mathrm{Ca}, \mathrm{Mg}, \mathrm{Zn}, \mathrm{Fe}, \mathrm{Pb}, \mathrm{Cd}, \mathrm{Sn}$ ) in urine by HPLC-AAS. G. Weber.

Durch Kombination von Reversed-Phase HPLC mit AAS können Metallionen in Urin mit einem Minimum an Probenvorbereitung analysiert werden. Dazu werden die filtrierten Urinproben direkt auf eine 
Spherisorb ODS 1-Säule unter Vorschaltung einer gleichen Schutzsäule injiziert und mit einem linearen Gradienten zwischen $0,04 \mathrm{~mol} / 1$ Phosphorsäure in Wasser und $0,04 \mathrm{~mol} / \mathrm{l}$ Phosphorsäure in Methanol getrennt. Der Nachweis der organischen Verbindungen erfolgt im UV bei $254 \mathrm{~nm}$. Die Metalle können durch on-line Kopplung der HPLCCapillare mit dem Nebulisator der AAS nachgewiesen werden. Mit Ausnahme von Blei, welches in Urin sowohl als Chlorid als auch als Sulfat vorliegt, sind die Metalle alle als Chloride oder Chlorokomplexe vorhanden. Der Einfluß von pharmazeutischen Wirkstoffen auf die Verteilung der Metallspezies wird mit diesem Verfahren untersucht. - J. Trace. Elem. Electrolytes Health Dis. 2, $61-65$ (1988). Inst. Spektrochem. Angew. Spektroskop., D-4600 Dortmund

R.H.S.

Comparison of physicochemical speciation procedures with metal toxicity Chlorella pyrenoidosa. G.M.P. Morrison and T.M. Florence.

Man mißt die Metallspeciation durch anodische Strippinguoltammetrie (ASV), Adsorption an einem Harz mit adsorbiertem hydratisiertem Aluminiumoxid und Dialyse mit einem aufnehmenden Harz (z. B. Chelex-100). Die dabei gefundenen Ergebnisse werden mit der Toxizität der betreffenden Metalle für die Süßwasser-Grünalge Chlorella pyrenoidosa Chick verglichen. In Gegenwart natürlicher (Humin-, Fulvin- und Gerbsäuren) oder synthetischer (NTA) Liganden werden ähnliche labile Fraktionen von Metallen bei der ASV an drei Elektroden (HMDE, MFE, Nafion-überzogene MFE) erhalten. Die sowohl mit ASV als auch durch den Bioassay bestimmten toxischen Fraktionen stimmen für die Elemente $\mathrm{Zn}, \mathrm{Cd}$ und $\mathrm{Cu}$ gut überein. Bei geringer Veränderung der analytischen Bedingungen trifft dies angenähert auch auf $\mathrm{Pb}$ zu. Weitere Vergleiche in bezug auf bestimmte Analysenbereiche (Adsorptionsverhalten, Dialyseverhalten u.ä.) werden diskutiert. - Anal. Chim. Acta 209, 97 109 (1988). CSIRO Div. Energy Chem., Menai, NSW (AUS)

Determination of non-protein-bound zinc in human serum using ultrafiltration and atomic absorption spectrometry with electrothermal atomisation. J.W. Foote and H.T. Delves.

Ultrafiltration through cellulose acetate membranes has been combined with electrothermal atomic absorption spectrometry to measure non-protein-bound zinc in serum. The retention of zinc-binding proteins by ultrafiltration membranes is virtually complete. The effects of the matrix on the sensitivity of the method for zinc are overcome by the use of a matrix modifying reagent and by the addition of amino acids to the calibration standards. To control the problems of contamination that are associated with the measurement of the metal at nanomolar concentrations, all equipment is washed with dilute hydrochloric acid before use and serum ultrafiltrates are analysed for zinc without preparative handling. The procedure is simple and requires only $400 \mu \mathrm{l}$ of serum for duplicate analyses. The relative standard deviation for the determination of an ultrafiltrable serum zinc concentration of $90 \mathrm{nmol}^{-1}$ is $10.8 \%$. The concentration of non-protein-bound zinc measured in sera from 17 healthy volunteers is $81 \pm 16 \mathrm{nmol}^{-1}$ with a range of $62-112 \mathrm{nmol}$ $1^{-1}$. The effect of $\mathrm{CO}_{2}$ loss from samples has been investigated and inaccuracies resulting from the use of heparin-treated plasma samples are described. - Analyst 113, $911-915$ (1988). Dept. Clin. Chem., Univ. Hosp., Queens Med. Centre, Nottingham (GB)

Isotope dilution spark-source mass spectrometric determination of total mercury in botanical and biological samples. J.R. Moody and P.J. Paulsen.

A combustion technique for the isolation of mercury from organic matrices is described which minimises the chemical blank. The operating parameters for isotope dilution spark source mass spectrometry have been optimized for these samples. Concentrations of ca. $0.1 \mu \mathrm{g} \mathrm{g}^{-1}$ in solid samples, such as tuna, leaves and urine, have been determined with a precision of about 4\%. - Analyst 113, 923-927 (1988). Center Anal. Chem., Nat. Bureau Standards, Gaithersburg, MD (USA)

Determination of lead in whole blood with a simple flow-injection system and computerized stripping potentiometry. L. Almestrand, M. Betti, Chi Hua, D. Jagner and L. Renman.

Für die Bestimmung von Blei in Konzentrationen bis $1000 \mu \mathrm{g} / \mathrm{l}$ in Humanblut auf der Basis eines Fließinjektionsverfahrens mit ablöse- potentiometrischer Bestimmung wird ein automatisiertes Verfahren für den Durchsatz von 24 Proben $/ \mathrm{h}$ beschrieben. Man verdünnt die Proben $20 \mathrm{fach}$ mit $0,5 \mathrm{M} \mathrm{HCl}$, die $100 \mathrm{mg} / \mathrm{l}$ Quecksilber(II) und $40 \mu \mathrm{g} / \mathrm{l} \mathrm{Cad}$ mium(II) enthält. 1,1 ml-Aliquots der Verdünnung werden in das FIASystem (Schemaskizze im Original) injiziert. Mit Hilfe einer mit $\mathrm{Hg}$ überzogenen Kohlefaser als Arbeitselektrode (gegen $\mathrm{Ag} / \mathrm{AgCl}$ ) bestimm man $\mathrm{Pb}(\mathrm{II})$ unter Verwendung einer Eichkurve, die aus Rinderblut hergestellt wurde; Cd(II) dient als innerer Standard. Bei der Analyse von zwei Standardreferenzblut-Proben mit Zertifikatwerten von 332 und $663 \mu \mathrm{g} / 1 \mathrm{~Pb}(\mathrm{II})$ wurden $335 \pm 37$ und $691 \pm 24 \mu \mathrm{g} / \mathrm{l} \mathrm{Pb}(\mathrm{II})$ gefunden. Anal. Chim. Acta 209, $339-343$ (1988). Dept. Techn. Anal. Chem., Chem. Center, Univ., Lund (S)

W. Czysz

Determination of chromium in human urine by graphite furnace atomic absorption spectrometry with Zeeman-effect background correction. P. Dube.

A rapid and direct method for the determination of chromium in human urine using graphite furnace atomic absorption spectrometry with Zeeman-effect background correction is described. No reagent or sample pre-treatment (except for straightforward dilution of concentrated samples with distilled water) was necessary, thereby reducing the risk of contamination. The concentration of chromium in urine was evaluated directly from a calibration graph constructed from a metalspiked human urine pool. Hence, the time consuming method of standard additions was avoided, which permitted an increased sample throughput (100-120 samples per day) with minimum attention of the analyst. In routine use, the reproducibility (both within-day and day-today) and limit of detection were in the order of $\pm 10 \%$ and $0.09 \mu \mathrm{g} \mathrm{l^{-1 }}$ of $\mathrm{Cr}$, respectively. With a minor alteration in charring temperature the method may also be used for the determination of chromium in whole blood and serum. The method described is suitable for the biological monitoring of chromium in the general population or in occupationally exposed persons. - Analyst 113,917-921 (1988). Inst. Water, Soil Air Hygiene, Federal Health Office, D-1000 Berlin 33

Determination of chromium oxidation state by $\mathrm{X}$-ray fluorescence spectrometry: Application to chromium(VI) and chromium(III) determination in occupational hygiene samples. J.M. Arber, D.S. Urch, and N.G. West.

The K X-ray emission lines of chromium in several oxidation states have been studied and changes in peak position and profile observed. The changes have been related to oxidation state and ligand environment. These observations were employed in the determination of the $\mathrm{Cr}(\mathrm{VI})$ to total $\mathrm{Cr}$ ratio by X-ray fluorescence spectrometry, the measurement of the $\mathrm{Cr} K \beta^{\prime}$ to $\mathrm{Cr}_{\mathrm{K}} \mathrm{K} \beta_{1,3}$ intensity ratio being chosen as the most appropriate parameter. The method was applied to the determination of the Cr(VI) content of welding fume samples. - Analyst 113, 779-782 (1988). Chem. Dept. Queen Mary College, London E1 (GB)

An ultrasensitive colorimetric assay for manganese. W.F. Beyer, Jr. and I. Fridovich.

Ein ultraempfindliches colorimetrisches Verfahren zur Mn-Bestimmung wird vorgeschlagen. Es beruht auf der katalytischen Wirkung von Mn(II) auf die photochemische Oxidation von o-Dianisidin, die durch Riboflavin ausgelöst wird. Das Bestimmungsgemisch mit maximaler Empfindlichkeit für $\mathrm{Mn}^{2+}$ enthält $22,5 \mathrm{ml} 50 \mathrm{mM}$ Phosphatpuffer $(\mathrm{pH}$ $7,8), 0,25 \mathrm{ml} 40,09 \mathrm{mM}$ o-Dianisidin, $0,62 \mathrm{ml} \%$ Triton X-100, 2,50 ml $1,17 \times 10^{-4} \mathrm{M}$ Riboflavin und $0,25 \mathrm{ml}$ Rinderleberkatalase $(10 \mathrm{mg} / \mathrm{ml})$ Zur Bestimmung wird $1 \mathrm{ml}$ obigen Gemisches mit $20 \mu \mathrm{l}$ Probe gemischt, $8 \mathrm{~min}$ bestrahlt und die Absorption bei $460 \mathrm{~nm}$ gemessen. Es wird ein Blindversuch gemacht. Im Gegensatz zu Katalase inhibiert Superoxiddismutase die Reaktion. Cu(II) stört die Bestimmung, Zn, Fe(II), Fe(III), $\mathrm{Co}(\mathrm{II})$ und $\mathrm{Ni}(\mathrm{II})$ dagegen nicht. Chelatisierende Agentien und thiolreduzierende Agentien stören die Bestimmung ebenfalls. Die Störung durch die organischen. Verbindungen kann durch nasse Veraschung und die durch $\mathrm{Cu}(\mathrm{II})$ durch Cyanidzugabe beseitigt werden. Im Bereich von $10-2500 \mathrm{nM}$ Mn(II) erhält man mit dem Verfahren eine lineare Anzeige. Die Nachweisgrenze wird mit $5 \mathrm{nM} \mathrm{Mn}(\mathrm{II})$ angegeben. - Anal. Biochem. 170, $512-519$ (1988). Dept. Biochem., Duke Univ. Med. Center Durham, NC (USA) 
Colorimetric detection of the hydroxyl radical: Comparison of the hydroxyl-radical-generating ability of various iron complexes. S. Singh and R.C. Hider.

Ein aromatisches Substrat zur Hydroxylierung von ${ }^{\circ} \mathrm{OH}-$ Radikalen wird synthetisiert. Das N,N'-(5-Nitro-1,3-phenylen)bis-glutaramid, welches durch Acetylierung von 3,5-Diaminonitrobenzol erhalten wird, weist ein Absorptionsmaximum bei $292 \mathrm{~nm}$ auf, die bei der Hydroxylierung entstehenden ortho- und para-Hydroxyverbindungen absorbieren bei 350 bzw. $310 \mathrm{~nm}$. Weder die hydroxylierten Produkte noch das Substrat binden Fe(III) oder Fe(II). Die Bestimmung der ${ }^{\circ} \mathrm{OH}-$ Radikale, die durch verschiedene Eisenkomplexe durch Fenton-Reaktion produziert werden, werden mit dem ortho-Hydroxyderivat durchgeführt. Das Reaktionsgemisch enthält in Boratpuffer $(\mathrm{pH} 8)$ das aromatische Substrat ( $5 \mathrm{mM} \mathrm{H}_{2} \mathrm{O}_{2}$ und verschiedene Konzentrationen von Eisenkomplexen. Das Reaktionsgemisch wird nach Inkubation mit Katalase behandelt. Die Extraktion der Reaktionsprodukte erübrigt sich, weil man eine gefärbte Lösung erhält, deren Absorption bei $430 \mathrm{~nm}$ direkt ausgewertet werden kann. - Anal. Biochem. 171, 47 - 54 (1988). Dept. Chem., Univ. Essex, Colchester, Essex (GB)

R.H.S.

Determination of trichloroacetic acid by differential pulse polarography Application to clinical analysis. F. Pergola, G. Pezzatini and P. Carrai.

Verff. beschreiben ein gleichstrompolarographisches Verfahren zur Bestimmung von Trichloressigsäure (TCA) in wäßriger Lösung und in Urin. Bei der Bestimmung in Urin wird folgende Vorbehandlung empfohlen: Man gibt zur Probe soviel festes $\mathrm{NaOH}$, daß eine $2 \mathrm{M}$ $\mathrm{NaOH}+$ iKonzentration erreicht wird. Dann zentrifugiert man $10 \mathrm{~min}$ bei $4000 \mathrm{Upm}$. Man mischt ein Aliquot der klaren Lösung mit einem gleichen Volumen $2 \mathrm{M}$ Tretraethylammoniumchloridlösung und überführt das Gemisch in die Polarographiezelle. Bei wäßrigen Lösungen entfällt die Vorbehandlung mit $\mathrm{NaOH}$. Die DPP-Kurven werden bei einer Pulshöhe von $50 \mathrm{mV}$ aufgenommen (GKE und Pt-Draht-Gegenelektrode). Der gemessene Peakstrom ist der TCA-Konzentration im interessierenden Bereich $(0-90 \mathrm{mg} / 1)$ proportional. RSD für $2 \mathrm{mg} / \mathrm{l}$ bzw. $25 \mathrm{mg} / \mathrm{l}$ TCA: $10 \%$ und 8\%. - Anal. Lett. 21, 977-991 (1988). Dip. Chim. Univ., Florenz (I)

W. Czysz

Determination of methyl ethyl ketone and its metabolites in urine using capillary gas chromatography. S. Kežić and A.C. Monster.

Die Bestimmung des Lösungsmittels Methylethylketon und seiner Metabolite 2-Butanol, 3-Hydroxy-2-butanon und der meso- und $d, l$ Isomeren von 2,3-Butandiol in Urin wird beschrieben. Die zu analysierenden Verbindungen werden aus der biologischen Matrix nach Hydrolyse der Konjugate über eine Octadecylsäule isoliert. Die Elution erfolgt nach Zusatz von 1-Butanol als internem Standard mit Dichlormethan. Für die gaschromatographische Bestimmung wird eine HP-1 Methylsilicongurnmi Capillare eingesetzt. Dic 2,3-Butandiolisomeren werden besser auf einer CP WAX 52 CB Polyethylenglycolsäule analysiert. Es wird temperaturprogrammiert gearbeitet. Der Nachweis wird mit einem FID durchgeführt. Für $\mathrm{S} / \mathrm{N}=2$ erhält man Nachweisgrenzen von $0,1-1,4$ $\mathrm{mg} / \mathrm{ml}$. Die Wiederfindungsraten liegen zwischen $50-70 \%$ für die 2,3Butandiolisomeren und bei $88-96 \%$ für die anderen Verbindungen. J. Chromatogr. 428, 275-280 (1988). Coronel Lab. Occup. Health, Univ., Amsterdam (NL)

R.H.S.

Capillary gas chromatographic determination of major and minor metabolites of aromatic solvents in human urine. $M$. Korn, $R$. Wodarz, K. Drysch and F.W. Schmahi.

Aromatic solvents are involved in manifold areas of industry and craft. Inhaled solvent vapors are a known health hazard to workers. For medical prevention and toxicological assay specific laboratory methods for urinary metabolites are necessary. An economical capillary GC procedure is described which is suitable for routine analysis of major metabolites, sensitive for the determination of minor metabolites, and effective for the separation of chiral metabolic intermediates. - J. High Resolut. Chromatogr. 11, 313-316 (1988). Inst. Arbeits- Sozialmed. Univ., Tübingen (D)

A one-vial method for routine extraction and quantification of free fatty acids in blood and tissue by HPLC. E. Jüngling and $\mathrm{H}$. Kammermeicr.
Zur quantitativen Bestimmung freier Fettsäuren in Humanblutserum und Rattenherzgewebe wird ein einfaches Verfahren entwickelt. Die freien Fettsäuren werden mit Freon 11 extrahiert. Die Extrakte werden eingedampft, in Aceton aufgenommen, erneut eingedampft und schließ lich die Fettsäuren im Rückstand mit 0,11\% 4-Brommethyl-7-methoxycoumarin, gelöst in wasserfreiem Aceton, $\mathrm{K}_{2} \mathrm{CO}_{3}$, und $0,07 \% 18-\mathrm{Krone}$ 6-ether in Acetonitril durch $30 \mathrm{~min}$ Erhitzen auf $60^{\circ} \mathrm{C}$ derivatisiert. $10 \mu \mathrm{l}$ der Coumarinfettsäure-haltigen Probe werden auf eine RP-8 LiChrocartSäule injiziert, die mit einer mobilen Phase aus Acetonitril/Wasser (83:17) betrieben wird. Der Nachweis kann bei 325/380 nm fluorimetrisch durchgeführt werden. Die Freon-Extraktion ist schnell und vollständig, weder wird ein hydrolytischer Abbau der Fettsäuren, noch eine oxidative Veränderung der ungesättigten Fettsäuren beobachtet. 15 freie Fettsäuren werden mit diesem Verfahren mit guter Reproduzierbarkeit und einer Wiederfindungsrate um 100\% quantitativ bestimmt. Freie Fettsäuren werden mit dieser Methode im Bereich von 20 pmol bis 20 nmol analysiert. - Anal. Biochem. 171, 150-157 (1988). Dept. Physiol. Med. Fak., TH Aachen (D)

R.H.S.

A non-enzymatic method for the determination of picomole amounts of lactate using HPLC: Its application to single muscle fibers. W.S. Simonides, Re. Zaremba, C. van Hardeveld and W.J. van der Laarse.

Ein Verfahren zur Bestimmung von Lactat wird beschrieben, welches auf der Veresterung von Lactat mit der UV-absorbierenden Verbindung $\alpha$-p-Dibromacetophenon beruht. Dazu werden die in $\mathrm{HClO}_{4}$ homogenisierten Gewebeproben mit $\mathrm{KHCO}_{3}$ neutralisiert und der Überstand des Zentrifugats zur Lactatbestimmung eingesetzt. Der Extrakt wird mit $\mathrm{KOH}$ alkalisch gemacht, eingedampft, in Acetonitril aufgenommen und $\alpha$-p-Dibromacetophenon und 18-Krone-6-ether zugefügt. Nach 20 min Reaktion bei $80^{\circ} \mathrm{C}$ wird abgekühlt und das Reaktionsgemisch durch HPLC auf einer LiChrosorb RP-8-Säule isokratisch mit Acetonitril/ Wasser (3:7) chromatographiert. Der Nachweis wird bei $254 \mathrm{~nm}$ im UV durchgeführt. Die Derivatisierungsausbeute unter optimierten Bedingungen wird mit besser als $97 \%$ angegeben, die Standardabweichung liegt unter 3\%. Die untere Nachweisgrenze wird zu $14+10$ pmol bestimmt. Die Güte des Verfahrens ist damit mit enzymatischen Verfahren vergleichbar. - Anal. Biochem. 169, 268 - 273 (1988). Lab. Physiol., Fac. Med., Free Univ., Amsterdam (NL)

R.H.S.

High pressure liquid chromatographic assay for salicylic acid and its metabolites. B.V. Shetty and S. Melethil.

Zur Bestimmung von Salicylsäure (SA), Gentisinsäure (GS), Salicylursäure (SU), Salicylacyl-glucuronid (SAG) im Harn von Ratten extrahiert man $S A, G S$ und $S U$ aus angesäuertem Harn in ein 50:50-Gemisch von Ethylacetat und Butylchlorid; SAG wird aus neutralem Harn nach Umwandlung mit Hydroxylamin zu Salicylhydroxamsäure extrahiert Die HPLC-Trennung erfolgt an einer $\mathrm{C}_{18}$-Säule (Zorbax ODS, $5 \mu \mathrm{m}$ ). Mobile Phase: $5-10 \%$ Acetonitril in 3\%iger Essigsäure. Quantifizierung im UV $(310 \mathrm{~nm})$. Außer den genannten Verbindungen kann man noch Salicylphenol-glucuronid rechnerisch bestimmen, indem man den Gesamtsalicylatgehalt ermittelt und davon die Summe der vier oben genannten Verbindungen subtrahiert. Wiederfindungsraten zwischen 90 und 108\%. Nachweisgrenzen: $10 \mu \mathrm{g} / \mathrm{ml} \mathrm{SA}$, SU und GS, $2,5 \mu \mathrm{g} / \mathrm{ml}$ SAG. - Anal. Lett. 21, 395-410 (1988). Schools Pharm./Med., State Univ., Kansas City, MO (USA)

W. Czysz

Reversed-phase ion-pair chromatography of straight- and branched chain dicarboxylic acids in urine as their 2 -nitrophenylhydrazides. $H$. Miwa and M. Yamamoto.

Dicarboxylsäuren können in Urin mit 2-Nitrophenylhydrazinhydrochlorid zu den entsprechenden Monohydraziden derivatisiert werden, diese können von den Monocarboxylsäure-Hydraziden durch ein zweistufiges Extraktionsverfahren mit Ethylacetat bei verschiedenen $\mathrm{pH}$ Werten getrennt werden. Die Monohydrazide von 11 gerad- und verzweigtkettigen Dicarboxylsäuren werden isokratisch durch ReversedPhase Ionenpaar-Chromatographie in $24 \mathrm{~min}$ auf einer ODS-Säule getrennt. Der $\mathrm{pH}$ der mobilen Phase wird in dem Acetonitril/ $/ \mathrm{KH}_{2} \mathrm{PO}_{4}$ $\mathrm{Na}_{2} \mathrm{HPO}_{4}$-Gemisch nach Wunsch eingestellt und als Gegenionen geeignete Konzentrationen $(0.005 \mathrm{M})$ von TMA, TEA oder TPA als Bromide zugesetzt. Gute Ergebnisse werden beispielsweise mit einem Acetonitril/ Phosphatpuffer-Gemisch von 12:88 unter Zusatz von 0,005 M TMA 
erhalten. 3,3-Dimethylgutarsäure wird als interner Standard eingesetzt. Die analytischen Ergebnisse zeigen eine gute Ausbeute und Reproduzierbarkeit. Das Verfahren kann als precolumn-Derivatisierungsschritt bei der HPLC-Analyse von Dicarboxylsäuren in Urinproben eingesetzt werden. - Anal. Biochem. 170, $301-307$ (1988). Fac. Pharm. Sci., Univ., Fukuoka (J)

R.H.S.

Rapid and simple procedure for the determination of urinary phenylacetic acid using derivatization in aqueous medium followed by electron-capture gas chromatography. J.T.F. Wong, G.B. Baker and R.T. Coutts.

Ein neues Bestimmungsverfahren für Phenylessigsäure, welches auf wäßriger extraktiver Derivatisierung mit anschließender GC/ECD beruht, wird beschrieben. Dazu werden die Urinproben mit p-Chlorphenylessigsäure als internem Standard versetzt und mit $6 \mathrm{M} \mathrm{HCl}$ hydrolysiert. Nach Abkühlung wird mit Phosphatpuffer (pH 6) versetzt, Toluol, Dicyclohexylcarbodiimid und Pentafluorophenol jeweils in Toluol/Acetonitril $(9: 1)$ zugegeben. Nach Reaktion und Zentrifugation wird mit 0,5 $\mathrm{M} \mathrm{NH}{ }_{4} \mathrm{OH}$ versetzt, erneut zentrifugiert und die organische Phasen gaschromatographisch auf einer SE-54 Quarzcapillarsäule mit einem Temperaturprogramm von $100-280^{\circ} \mathrm{C}$ unter Verwendung von $\mathrm{He} / \mathrm{CH}_{4}$ (95:5) als Trägergas analysiert. Der Nachweis wird massenspektrometrisch und mit einem ${ }^{63} \mathrm{Ni}$-ECD durchgeführt. Für das Verfahren werden höchstens $25 \mu 1$ Urin benötigt. Die untere Nachweisgrenze ( $\mathrm{S} / \mathrm{N}=2)$ liegt unter $3 \mathrm{ng}$ (5 pg injiziert). - J. Chromatogr. 428, 140-146 (1988). PMHAC Res. Unit., Dept. Psych., Fac. Pharm., Pharm. Sci., Univ. Alberta, Edmonton, Alberta (CDN) R.H.S.

Sensitive determination of denterated and nondeuterated indole-3-acetic acid and 5-hydroxyindole-3-acetic acid by combined capillary gas chromatography-negative-ion chemical ionization mass spectrometry. T. Hayashi, H. Naruse, F. Matsuda and Y. Iida.

Empfindliche Verfahren zur Bestimmung deuterierter und nichtdeuterierter Indol-3-essigsäure und 5-Hydroxyindol-3-essigsäure durch kombinierte Capillar-GC/NICI-MS werden beschrieben. Dazu werden die Verbindungen in ihre Pentafluorbenzyl- bzw. Trifluoracetylmethylderivate nach Vorreinigung durch HPLC umgewandelt. Diese Derivate werden dann durch GC/MS getrennt und bestimmt. Als interne Standards

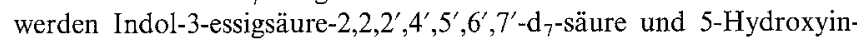
dol-3-essigsäure-3,3-d $\mathrm{d}_{2}$-säure verwendet. - J. Chromatogr. 428, $209-$ 219 (1988). Nat. Center Neurol., Kodaira, Tokyo (J) R.H.S.

Simultaneous determination of plasma phenethylamine, phenylethanolamine, tyramine and octopamine by high-performance liquid chromatography using derivatization with fluorescamin. T. Yonekura, S. Kamata, M. Wasa, A. Okada, A. Yamatodani, T. Watanabe and H. Wada.

Die aromatischen Amine Phenethylamin, Phenylethanolamin, Tyramin und Octopamin können aus biologischen Flüssigkeiten empfindlich in Form ihrer Fluorescaminderivate nach HPLC -Trennung bestimmt werden. Benzylamin wird den mit $\mathrm{Na}_{2}$ EDTA und $\mathrm{Na}_{2} \mathrm{~S}_{2} \mathrm{O}_{3}$ zentrifugierten Blutproben dabei als interner Standard zugesetzt. Dann wird mit $2,5 \% \mathrm{HClO}_{4}$ deproteinisiert und nach Alkalisierung mit $2 \mathrm{M} \mathrm{KOH}$ über eine Amberlit CG-50 Säule extrahiert. Die Catecholamine werden mit $0,8 \mathrm{M} \mathrm{Li}_{3} \mathrm{BO}_{3}$ eluiert, die basischen Aminosäuren mit 0,1 M Phosphatpuffer (pH 6.5) + EDTA und die aromatischen Amine schließlich mit $1 \mathrm{M}$ Natriumphosphatpuffer $(\mathrm{pH} 8,5)+5 \mathrm{mM} \mathrm{Na}_{2}$ EDTA. Dann wird mit Fluorescamin derivatisiert. Die Derivate werden mit Ethylacetat extrahiert und auf einer ODS-120 T-Säule mit einer mobilen Phase aus $0,05 \mathrm{M}$ Citratpuffer ( $\mathrm{pH} 2,5) /$ Methanol/Ethylacetat $(42: 40: 18)$ chromatographiert. Der Nachweis erfolgt fluorimetrisch bei $390 / 475 \mathrm{~nm}$. Die unteren Nachweisgrenzen lagen für die Amine bei $0,2 \mathrm{pmol} / \mathrm{ml}$. Lineare Eichkurven erhält man von $2-80 \mathrm{pmol} / \mathrm{ml}$. - J. Chromatogr. 427, $320-325$ (1988). Dept. Pediatric Surgery Univ. Osaka, Fukushima, Osaka (J)

R.H.S.

Determination of carnitine by high-performance liquid chromatography using 9-anthryldiazomethan. T. Yoshida, Y. Aetake, H. Yamaguchi, N. Nimura and T. Kinoshita.

Ein HPLC-Verfahren zur Bestimmung von Carnitinchlorid unter Verwendung von 9-Anthryldiazomethan (ADAM) als pre-column Derivatisierungsreagens wird beschrieben. Carnithinchlorid und der interne Standard N,N-Dimethylglycin reagieren mit ADAM in Gegenwart von
Natriumdodecylsulfat unter Bildung stabiler Esterderivate. Die ADAMDerivate von Carnitin und dem internen Standard können durch HPLC auf Silicagelsäulen mit Methanol/5\% wäßr. SDS/Phosphorsäure $(990: 10: 1)$ als mobiler Phase chromatographiert und von Zersetzungsprodukten des Reagens und verwandten Verbindungen wie Aminosäuren abgetrennt werden. Die Eichkurve ist im Bereich von $0,02-100$ ng pro Injektion linear. Die Nachweisgrenze für Carnitinchlorid liegt bei fluorimetrischer Detektion bei $365 / 412 \mathrm{~nm}$ bei $1 \mathrm{pg}$ pro Injektion $(\mathrm{S} / \mathrm{N}=4)$. - J. Chromatogr. 445, 175-182 (1988). School Pharm. Sci., Kitasato Univ., Tokyo (J)

R.H.S.

Direct ${ }^{1} H$ NMR determination of the enantiomeric excess of carnitine. J. Bounoure and J. Souppe.

The enantiomeric purity of carnitine may be determined without any derivatisation of the molecule. Preparations of aqueous mixtures containing stereochemically pure L-malic acid, carnitine and europium trichloride lead to the formation of a complex in which the trimethylammonium groups of $\mathrm{D}$ - and L-carnitine are diastereotopic. The resolution is observed only when strict experimental conditions are maintained. Analyst 113, $1143-1144$ (1988). Group. Rech. Lacq, Artix (F)

Fully enzymatic colorimetric assay of serum and urine creatinine which obviates the need for sample blank measurements. J. Siedel, R. Deeg, $H$. Seidel, H. Möllering, J. Staepels, H. Gauhl and J. Ziegenborn.

Verff. beschreiben ein enzymatisches Verfahren mit colorimetrischer Endbestimmung von Kreatinin in Blutserum und Urin, bei dem keine Probenblindlösungsmessungen erforderlich sind. Grundlage ist die Bildung von $\mathrm{H}_{2} \mathrm{O}_{2}$ bei einer Sequenz von Reaktionen, an denen KreatininIminohydrolyse, ATP-abhängige 1-Methylhydantoinase, N-Carbamoylsarkosin-Amidohydrolase und Sarkosin-Oxidase beteiligt sind. Der Reaktionsablauf wird genau beschrieben. Das zum Schluß im Zusammenwirken eines chromogenen Systems entstehende $\mathrm{H}_{2} \mathrm{O}_{2}$ wird bei $546 \mathrm{~nm}$ photometriert. An dem chromogenen System sind beteiligt Peroxidase, 2'-Sulfo-2-methylbenzthiazolinhydrazon und 2,4,6-Tribrom-3-hydroxybenzoesäure. Für eine Bestimmung wrden nur $20 \mu \mathrm{l}$ Probe benötigt, die Gesamtanalyse erfordert maximal $10 \mathrm{~min}$ (bei $25^{\circ} \mathrm{C}$ ). Die Präzision (within-run; CV) beträgt 3,1 und 1,6\% in Blutserum bei Kreatininkonzentrationen von 79 und $160 \mu \mathrm{mol} / \mathrm{l}$. Die Standardkurve ist aufwärts linear bis mindestens $1760 \mu \mathrm{mol} / \mathrm{l}$. - Anal. Lett. 21, 1009-1017 (1988). Boehringer Mannheim GmbH, Biochem. Res. Center, D-8132 Tutzing W. Czysz

Determination of creatinine in whole blood, plasma and urine by highperformance liquid chromatography. G.-P. Xue, R.C. Fishlock and A.M. Snoswell.

Ein empfindliches Verfahren zur spezifischen Bestimmung von Kreatinin in Gesamtblut, Plasma und Urin von hoher Genauigkeit wird beschrieben. Dazu werden die Proben mit Acetonitril deproteinisiert und durch HPLC auf einer Kationenaustauschersäule mit einer mobilen Phase aus 9\% Acetonitril in $40 \mathrm{mM}$ Ammoniumphosphat (pH 4) chromatographiert. Der UV-Nachweis kann bei $215 \mathrm{~nm}$ im UV erfolgen. Die Wiederfindungsraten für Kreatinin liegen zwischen 99 und 101\%. Für Blut und Plasma erhält man Variationskoeffizienten von $1,6 \%$ und für Urin von $1,5 \% .2 \mu \mathrm{l}$ Blut oder $0,02 \mu \mathrm{l}$ Urin sind für die chromatographische Analyse ausreichend. - Anal. Biochem. 171, 135-140 (1988). Dept. Animal Sci., Waite Agric. Res. Inst., Univ., Adelaide (AUS)

R.H.S.

Quantification of 3-hydroxykynurenine in brain by high-performance liquid chromatography and electrochemical detection. M.P. Heyes and B.J. Quearry.

Zur Bestimmung von 3-Hydroxykynurenin, einem Ausscheidungsprodukt des L-Tryptophan-Catabolismus, in Hirngewebe wird ein HPLCVerfahren entwickelt. Dazu werden die Perchlorsäureextrakte der Gewebeproben mit Dihydroxybenzylamid als internem Standard versetzt. Die Extrakte werden auf einer Ultrasphere ODS-Säule mit Wasser/ Acetonitril/Triethylamin/Phosphorsäure (950:20:9:5,9) unter Zusatz von $100 \mathrm{mg}$ NaEDTA und $1,8 \mathrm{~g}$ Heptansulfonsäure pro $1000 \mathrm{ml}$ als mobiler Phase chromatographiert. Der Nachweis erfolgt amperometrisch bei 0,55 oder $0,60 \mathrm{~V}$ gegen eine $\mathrm{Ag} / \mathrm{AgCl}-\mathrm{Vergleichselektrode}$. Im Bereich von $0-2000$ fmol erhält man eine lineare Eichkurve, die 
Nachweisgrenze wird bei $\mathrm{S} / \mathrm{N}=5 \mathrm{mit} 175 \mathrm{fmol}$ angegeben. - J. Chromatogr. 428, $340-344$ (1988). Lab. Neurophysiol., Lab. Clin. Chem., Nat. Inst. Mental Health, Bethesda, MD (USA) R.H.S.

Development of an HPLC assay for the analysis of tetrafluoroputrescine a putrescine analog. A.A. Hawi, H. Yip, T.S. Sullivan and G.A. Digenis.

Ein einfaches Reversed-Phase HPLC-Verfahren mit UV-Detektion bei $254 \mathrm{~nm}$ wird entwickelt, um Tetrafluoroputrescin (TFP) zu bestimmen. Die Derivatisierung von TFP mit Dansylchlorid bei $\mathrm{pH}$ 6,8-7,5 wird bei $60^{\circ} \mathrm{C}$ in pre-column Arbeitsweise durchgeführt. Die Trennung von Putrescin (PUT) erfolgt auf einer $\mathrm{C}_{18}$-Säule mit Methanol/Wasser $(75: 25)$ als mobiler Phase. Die Reaktionsbedingungen für die Derivatisierungsmethode werden so gewählt, daß die gleichzeitige Bestimmung von TFP und PUT in Gesamtblut möglich ist. - Anal. Biochem. 172, 235 -240 (1988). Div. Med. Chem., Coll. Pharm., Univ. Kentucky, Lexington, KY (USA)

R.H.S.

Automatic determinationof serotonin in biological fluids by liquid chromatography. P. Neblinger and M. Koel.

Ein neues Verfahren ohne Probenextraktion wird zur automatischen klinischen Serotoninbestimmung in biologischen Flüssigkeiten eingesetzt. Dazu werden einfach die mit $\mathrm{HClO}_{4}$ zentrifugierten Proben mit mobiler Phase verdünnt und in den Autosampler injiziert. Die Trennung erfolgt auf einer LiChrospher RP 18e-Säule unter Vorschaltung einer analogen Schutzsäule mit $5 \mathrm{mM}$ Octansulfonsäure in $0,1 \mathrm{M} \mathrm{NaH}_{2} \mathrm{PO}_{4}$ Phosphorsäure-Puffer (pH 3) in 25\% Methanol. Der fluorimetrische Nachweis wird bei $285 / 345 \mathrm{~nm}$ durchgeführt. Eine Analyse dauert nur 12 min. Serotoninkonzentrationen unter $10 \mathrm{ng} / \mathrm{ml}$ sind mit diesem Verfahren gut nachweisbar. - J. Chromatogr. 427, 326-330 (1988). Med. Lab., Dr. Enzenauer \& Dr. Wilhelm, D-4500 Osnabrück R.H.S.

1,2-Diarylethylendiamines as fluorogenic reagents for catecholamines. Y. Umegae, H. Nohta and Y. Ohkura

Bei der Suche nach einem hochempfindlichen fluorogenen Reagens für die Bestimmung von Catecholaminen (Norepinephrin, Epinephrin und Dopamin) wurden 28 1,2-Diarylethylendiamine getestet. Alle reagieren mit Epinephrin als einem Modell-Catecholamin unter milden Bedingungen $\left(\mathrm{pH} 6,5-6,8 ; 37-50^{\circ} \mathrm{C}\right)$ in Gegenwart von Kaliumhexacyanoferrat(III). Die meso-Formen von 1,2-Bis(3,4-dimethoxyphenyl)ethylendiamin, 1,2-Bis(4-methoxyphenyl)ethylendiamin und 1,2-Bis(4-ethoxyphenyl)ethylendiamin waren die bei allen Catecholaminen am empfindlichsten reagierenden Verbindungen. Die Catecholamine können in Konzentrationen abwärts bis $10-15 \mathrm{pmol} / \mathrm{ml}$ bestimmt werden Störungen durch andere Biomoleküle wurden nicht beobachtet. - Anal. Chim. Acta 208, 59 - 68 (1988). Fac. Pharm. Sci., Kyushu Univ., Higashi-ku, Fukuoka (J)

W. Czysz

Amino acid analysis by dinitrophenylation and reverse-phase high-pressure liquid chromatography. R.C. Morton and G.E. Gerber.

Aminosäuren können in Form ihrer Dinitrophenylderivate durch Reversed-Phase HPLC bestimmt werden. Zur Bestimmung werden die Proteinhydrolysate in Ethanol/Wasser/Triethylamin (2:3:1) gelöst, 67 $\mathrm{mM}$ ethanolischer Lösung von Fluoro-2,4-dinitrobenzol zugegeben und $30 \mathrm{~min}$ bei $50^{\circ} \mathrm{C}$ derivatisiert. Dann wird durch Zusatz von Eisessig angesäuert, eingedampft, erneut angesäuert und eingedampft und schließlich in Ethanol/Wasser/Triethylamin aufgenommen. Nach Ansäuern kann auf einer Altex Ultrasphere ODS-Säule $\left(\mathrm{C}_{18}\right.$-gebunden) mit $60 \mathrm{mM}$ Natriumacetat ( $\mathrm{pH} 4,45$ )/Methanol-Gemischen getrennt werden Der Nachweis erfolgt bei $365 \mathrm{~nm}$. Das Verfahren eignet sich zur Bestimmung von Aminosäuren bis hinunter in den unteren Picomol-Bereich. Die Vorteile gegenüber anderen Verfahren werden diskutiert. - Anal Biochem. 170, 220 - 227 (1988). Dept. Biochem., McMaster Univ., Hamilton, Ontario (CDN)

R.H.S.

Liquid chromatographic determination of amino acids using a hollow-fiber membrane reactor. J. Haginaka and J. Wakai.

Ein HPLC-Verfahren unter Verwendung eines passiven HohlfiberMembranreaktors (HFMR) wird zur Bestimmung von Aminosäuren entwickelt. Das Verfahren gestattet die Gradientenelution der 18 gebräuchlichen Aminosäuren auf einer $\mathrm{C}_{18}$-Säule unter Verwendung von Natriumoctansulfonat als Ionnenpaarungsreagens in einem Phosphat-
puffer/Methanol-Gemisch. Dann erfolgt eine post-column Derivatisierung mit o-Phthalaldehyd und 2-Mercaptoethanol (kombiniert mit einer Hypochloritoxidation der Iminosäure Prolin). Diese Derivatisierung erfolgt durch Zwischenschaltung von aminierten und sulfonierten HFMRs, die in Hypochlorit bzw. OPA-2-ME immersiert wurden. Die fluorimetrische Detektion der Derivate kann bei 340/450 nm durchgeführt werden. Die Nachweisgrenzen des vorgeschlagenen Verfahrens liegen bei $0,4-20 \mathrm{pmol}$ für jede Aminosäure bei einem S/N-Verhältnis von 3. Im Bereich von $250-2500$ pmol der 18 Aminosäuren liegen die Genauigkeiten um 1,5-4,8\% (rel. Standardabweichung, $n=10$ ). Das Verfahren wird auf die Aminosäureanalyse in einem Proteinhydrolysat angewandt. - Anal. Biochem. 171, 398-403 (1988). Fac. Pharm. Sci. Mukogawa, Women's Univ., Nishinomiya, Hyogo (J) R.H.S.

Stereoselective determination of L-amino acids using column liquid chromatography with an enzymatic solid-phase reactor and chemiluminescence detection. H. Jansen, U.A.T. Brinkman and R.W. Frei.

Ein stereoselektives post-column Reaktionsverfahren zum Nachweis von $8 \mathrm{~L}$-Aminosäuren wird beschrieben, welches auf der Verwendung eines Reaktors beruht, der mit immobilisierter L-Aminosäureoxidase gepackt ist. Es wird mit auf Glaskugeln immobilisiertem Enzym gearbeitet. Die L-Aminosäure wird dabei zur 2-Oxosäure umgewandelt und kann aufgrund der Peroxyoxalat-Chemiluminiscenz extrem selektiv nachgewiesen werden. Das Detektionssystem zeigt über zwei Zehnerpotenzen eine lineare Anzeige und die Nachweisgrenzen liegen im Bereich von $0,35 \times 10^{-6}$ bis $3,0 \times 10^{-6} \mathrm{M}$. Das Verfahren wird hier zur Bestimmung ausgewählter Aminosäuren in Urin und Bier eingesetzt. -- J Chromatogr. 440, 217-223 (1988). Dept. Anal. Chem., Free Univ., Amsterdam (NL)

R.H.S.

Determination of methylated amino acids in human serum by high-performance liquid chromatography. K.S. Park, H.W. Lee, S.-Y. Hong, S Shin, S. Kim and W.K. Paid.

$\mathrm{N}^{\mathrm{G}}$-Monomethylarginin (MMA), $\mathrm{N}^{\mathrm{G}}$-Dimethylarginine und $\varepsilon-\mathrm{N}$-Methyllysin (TML) können quantitativ aus Serumproben nach Deproteinisierung mit Trichloressigsäure und Reinigung über eine Dowex $50\left(\mathrm{H}^{+}\right)$ Säule getrennt werden. Die Methyl- und Acetylderjvate werden durch ein Zweisäulensystem ( $\mu$ Bondapak $\mathrm{C}_{18}$ und $\mu$ Bondapak $\mathrm{CN}$ ) isokratisch mit $25 \mathrm{mM} \mathrm{Na}_{2} \mathrm{HPO}_{4}$ in Methanol/Tetrahydrofuran/Wasser $(34: 1: 65)$ bei pH 7,4 getrennt. Dann wird Phenylisothiocyanat als fluorogenes Reagens zugesetzt. Der fluorimetrische Nachweis der Derivate erfolgt bei $338 / 425 \mathrm{~nm}$. Vergleichsweise werden auch o-Phthalaldehyd-Derivate untersucht. Die Wiederfindungsraten liegen über $90 \%$. - J. Chromatogr. 440, 225-230 (1988). Fels Res. Inst., Temple Univ. School Med. Philadelphia, PA (USA)

R.H.S

Resolution of $\alpha$-substituted amino acid enantiomers by high-performance liquid chromatography after derivatization with a chiral adduct of 0 phthalaldehyde. Application to glutamic acid analogues. M. Maurs, F. Trigalo and R. Azerad.

$\alpha$-Substituierte enantiomere Aminosäuren werden mit o-Phthalaldehyd und N-Acetyl-L-Cystein in Boratpuffer (pH 10) durch 3 min Reaktion derivatisiert und durch HPLC auf einer Nucleosil $5 \mathrm{C}_{18}$-Säule unter Verwendung von Phosphatpuffer $(\mathrm{pH} 7,5) /$ Methanol-Gemischen chromatographisch getrennt. Der fluorimetrische Nachweis kann bei $345 / 445 \mathrm{~nm}$ durchgeführt werden. Das Verfahren eignet sich besonders zur analytischen Auftrennung $\alpha$-substituierter Glutaminsäureanaloger, wie 2-Methylglutaminsäure und einiger cyclischer Analoge wie 1-Amino1,3-dicarboxycyclohexan, 1-Amino-1,3-dicarboxy-2-cyclohexen und 1Amino-1,3-dicarbocyclopentan. Die Reihenfolge der Elution von der Säule wird in Beziehung zur absoluten Konfiguration der Derivate gebracht. - J. Chromatogr. 440, $209-215$ (1988). Lab. Chim. Biochim. Pharmacol. Toxicol, Univ. Descartes, Paris (F) R.H.S.

High-performance liquid chromatographic analysis of neurotransmitter amino acids in brain. T.A. Durkin, G.M. Anderson and D.J. Cohen

Neurotransmitter-Aminosäuren können in Hirngewebe gut in Form ihrer o-Phthalaldehyd/3-Mercaptopropionsäurederivate durch HPLC/ Fluorimetrie bestimmt werden. Dazu werden die mit $\mathrm{HClO}_{4}$ homogenisierten Proben mit Homoserin und $\delta$-Aminovaleriansäure als internen Standards versetzt. Nach Zentrifugation wird der Überstand mit Metha- 
nol, Boratpuffer und Reagenslösung nach H. Godel, T. Graser, P. Foldi, P. Pfaender und P. Fürst (J. Chromatogr. 297, 49 (1984)) chromatographiert. Das Reaktionsgemisch kann direkt auf einer Ultrasphere $5 \mu \mathrm{m}$ ODS-Säule analysiert werden. Für die Bestimmung von Asp, Glu, Homoserin, Tau und Gly wird 0,57\% Acetatpuffer ( $\mathrm{pH} 3,75)$ /Acetonitril $+\mathrm{Na}_{2}$ EDTA $(100 \mathrm{mg} / \mathrm{ml})(75: 25)$ als mobile Phase verwendet. Für die GABA Analyse beträgt das Verhältnis 1:1 und es wird 0,2 M Acetatpuffer $(\mathrm{pH} 3,8)$ verwendet. Der fluorimetrische Nachweis kann bei 330/440 $\mathrm{nm}$ durchgeführt werden. Die Analysen dauern weniger als $12 \mathrm{~min}$. J. Chromatogr. 428, 9-15 (1988). Child Study Center, Dept. Lab. Med., Yale Univ. School Med., New Haven, CT (USA)

R.H.S.

Enzymatic determination of L-phenylalanine and phenylpyruvate with $L$ phenylalanine dehydrogenase. $W$. Hummel, H. Schütte and M.-R. Kula.

Ein enzymatisches Verfahren zur Bestimmung von L-Phenylalanin oder Phenylpyruvat unter Verwendung von L-Phenylalanindehydrogenase wird beschrieben. Das Enzym katalysiert die NAD-abhängige oxidative Bestimmung von L-Phenylalanin oder die reduktive Aminierung der 2-Oxo-säure. Durch stöchiometrische Kupplung des Enzyms wird eine direkte spektralphotometrische Bestimmung der Substratkonzentration möglich. L-Phenylalanin kann im Bereich von $10-300 \mu \mathrm{M}$ und Phenylpyruvat von $5-100 \mu \mathrm{M}$ mit linearer Anzeige bestimmt werden. Neben Phenylalanin kann das Enzym Tyrosin und Methionin und ihre Oxosäuren umwandeln, die $\mathbf{K}_{\mathrm{m}}$-Werte dieser Substrate liegen jedoch höher. Der Einfluß von Tyrosin auf die Bestimmung von Phenylalanin wird untersucht und erscheint für bestimmte Anwendungen tolerierbar. - Anal. Biochem. 170, 397-401 (1988). Ges. Biotechnol. Forsch. $\mathrm{mbH}, \mathrm{D}-3300$ Braunschweig

R.H.S.

Determination of $D, L$-threo-dihydroxyphenylserine and the $D$ - and $L$ enantiomers in human plasma and urine. F. Boomsma, F.A.J. van der Hoorn, A.J. Man in't Veld and M.A.D.H. Schalekamp.

D,L-threo-3,4-Dihydroxyphenylserin (DOPS), ein nichtphysiologischer Vorgänger der Aminosäure Norepinephrin, der zur Behandlung verschiedener Erkrankungen des sympathischen Nervensystems eingesetzt wird, kann in Humanplasma und -urin durch ein HPLC-Verfahren bestimmt werden. L-DOPS wird durch aromatische L-Aminosäuredecarboxylase in vitro in natürliches Norepinephrin umgewandelt, DDOPS inhibiert diese Reaktion. Um die Wechselwirkung von D- und LDOPS in vivo zu untersuchen, wird hier ein Reversed-Phase HPLCVerfahren entwickelt. Die Extraktion aus den physiologischen Flüssigkeiten erfolgt nach dem bereits früher beschriebenen Verfahren von $\mathrm{F}$. Boosma, F.A.J. van der Hoorn und M.A.D.H. Schalekamp (Clin. Chim. Acta 159, 173 (1986)). D- und L-threo-DOPS werden dann mit o-Phthaldialdehyd und N-Acetyl-L-cystein derivatisiert. Die Derivate werden auf einer MicroSpher $\mathrm{C}_{18}$-Säule mit einem linearen Gradienten von Tetrahydrofuran/Methanol $(2: 1)$ in $0,05 \mathrm{M}$ Natriumphosphat $(\mathrm{pH} 6,5)$ getrennt. Der Nachweis kann fluorimetrisch erfolgen. Die Trennfaktoren liegen bei 2,33. Außerdem werden noch zwei einfache und empfindliche Verfahren zur Bestimmung des Gesamtgehaltes an D,L-DOPS beschrieben, bei denen beim einen eine Deproteinisierung mit $\mathrm{HClO}_{4}$ und beim anderen eine Flüssig-flüssig-Extraktion als Probenaufarbeitung verwendet wird. Hier kann nach HPLC-Trennung elektrochemisch nachgewiesen werden. Man erhält gut übereinstimmende Ergebnisse. - J Chromatogr. 427, 219-227 (1988). Dept. Intern. Med. I., Univ. Hosp. Dijkzigt, Erasmus Univ., Rotterdam (NL)

R.H.S.

Analysis of $\gamma$-carboxyglutamic acid by reverse phase HPLC of its phenylthiocarbamyl derivative. D.M. Smalley and P.C. Preusch.

Ein Verfahren zur Analyse von $\gamma$-Carboxyglutaminsäure, welches auf deren Derivatisierung mit Phenylisothiocyanat und Reversed-Phase HPLC der erhaltenen Phenylthiocarbamylderivate beruht, wird beschrieben. Zur Analyse von Carboxyglutaminsäure-haltigen Proteinen werden diese vor der Analyse mit $\mathrm{NaOH}$ hydrolysiert und die Hydrolysate über eine Dowex 50-Säule entsalzt. Die Elution erfolgt mit $\mathrm{NH}_{4} \mathrm{OH}$ Das resultierende Aminosäuregemisch wird mit Phenylisothiocyanat derivatisiert und die Phenylthiocarbamylderivate unter isokratischen Bedingungen entweder auf einer $\mathrm{C}_{18}$ - oder einer $\mathrm{C}_{8}$-Reversed-Phase-Säule mit $0,14 \mathrm{M}$ Tris, $0,05 \%$ Triethylamin ( $\mathrm{pH} 7,5$ mit Eisessig) $+2 \%$ Acetonitril chromatographiert. Der Nachweis kann im UV bei $254 \mathrm{~nm}$ durchgeführt werden. Im Bereich von $10-1000$ pmol $\gamma$-Carboxygluta- minsäure erhält man eine lineare Eichkurve. Die Nachweisgrenze liegt bei 2 pmol. - Anal. Biochem. 172, 241 - 247 (1988). Dept. Chem., Univ. Akron, OH (USA)

R.H.S.

High-performance liquid chromatographic method for the determination of $\varepsilon$ - $(\gamma$-glutamyl)lysine and mono- and bis- $\gamma$-glutamyl derivatives of putrescine and spermidine. S. Beninati, N. Martinet and J.E. Folk.

Ein empfindliches, einfaches und schnelles HPLC-Verfahren zur Bestimmung von $\varepsilon$ - $(\gamma$-Glutamyl)lysin und bestimmten $\gamma$-Glutamylpolyaminen aus ausgewählten Fraktionen von Ionenaustauschchromatogrammen von Proteinaufschlüssen wird beschrieben. Das Verfahren arbeitet mit pre-column Derivatisierung der $\gamma$-Glutamylaminkonjugate mit $o$ Phthalaldehyd, einem linearen Gradienten von $10 \mathrm{mM}$ Natriumacetat (pH 5) bis $10 \mathrm{mM}$ Natriumacetat/Acetonitril $(20: 80)$ auf einer $\mu$ Bondapak $\mathrm{C}_{18}$-Säule und fluorometrischem Nachweis bei $340 / 440 \mathrm{~nm}$. Mit dem verwendeten Gradienten wird ein Entsalzungsschritt bei Aufrechterhaltung geeigneter chromatographischer Bedingungen erreicht. Im Bereich von $0,1-1 \mathrm{nMol} \gamma$-Glutamylamin erhält man lineare Anzeigen. Die Nachweisgrenzen werden mit 10 und $200 \mathrm{pm}$ pro mg Protein für $\gamma$ Glutamylpolyamine bzw. für $\varepsilon-(\gamma$-Glutamyl)lysin angegeben. Die Verwendung des Verfahrens für bestimmte Gewebe wird demonstriert. J. Chromatogr. 443, 329-335 (1988). Lab. Oral. Biol. Physiol., Nat. Inst. Dental Res., Nat. Inst. Health, Bethesda, MD (USA) R.H.S.

Measurement of cyst(e)amine in physiological samples by high-performance liquid chromatography. R.A.G. Garcia, L.L. Hirschberger and M.H. Stipanuk.

Zwei Verfahren zur Bestimmung von Cyst(e)amin in physiologischen Proben wird beschrieben. Ein Verfahren beruht auf der Reduktion der in der Probe befindlichen Disulfide mit Tributylphosphin und HPLCTrennung der Thiole auf einer Spherisorb ODS-Säule unter Vorschaltung einer $\mu$ Bondapak $\mathrm{C}_{18}$-Säule mit $25 \mathrm{mM}$ Monochloracetat ( $\mathrm{pH}$ ), $0,5 \mathrm{mM}$ Octylnatriumsulfat, $0,015 \%$ EDTA und $2 \%$ Methanol. Cysteamin und die anderen Thiole werden elektrochemisch bei $+0,2 \mathrm{~V}$ in oxidierender Arbeitsweise mit einer Goldamalgamelektrode nachgewiesen. Beim anderen Verfahren werden die Disulfide mit Dithiothreit reduziert, die Thiole mit 7-Diethylamino-3-(4'-malimidylphenyl)-4-methylcoumarin derivatisiert und die Derivate auf einer Reversed-Phase $\mathrm{C}_{18}$ Säule mit einem binären Gradienten aus Natriumacetat ( $\mathrm{pH}$ 6) und Acetonitril getrennt. Die Derivate können fluorimetrisch bei $387 / 465 \mathrm{~nm}$ nachgewiesen werden. Die Cyst(e)amin-Gehalte verschiedener Gewebe werden mit diesen Verfahren vergleichend untersucht. - Anal. Biochem. 170, 432-440 (1988). Div. Nutrit. Sci., Comell Univ., Savage Hall, Ithaca, NY (USA)

R.H.S.

Resolution of stereoisomers of dipeptides by gas chromatography on Chirasil-Val. B. Koppenhoefer, H. Allmendinger, K.P. Chang and L.B. Cheng.

Verschiedene Dipeptide können gaschromatographisch auf ChirasilVal in ihre Stereoisomeren (Enantiomeren, Diastereomeren, Sequenzisomeren) getrennt werden. Dazu werden die Dipeptide in ihre N-Trifluoracetyldipeptidmethylester bei Zimmertemperatur umgesetzt, dadurch wird eine Racemisierung bzw. Epimerisierung sowie eine Aufspaltung der Peptidbindung vermieden. Das Verfahren eignet sich zur Untersuchung der stereoisomeren Zusammensetzung von Dipeptiden in biologischen Proben. - J. Chromatogr. 441, 89-98 (1988). Inst. Organ Chem., Univ., Tübingen (D)

R.H.S.

Rapid analysis of proteins and peptides by reversed-phase chromatography with polymeric micropellicular sorbents. Y.-F. Maa and C. Horváth.

Peptide und Proteine können durch Reversed-Phase HPLC auf $30 \times 4,6 \mathrm{~mm}$ i. D. Säulen, die mit nichtporösen vernetzten Polystyrolteilchen mit einem mittleren Teilchendurchmesser von $3 \mu \mathrm{m}$. gepackt sind, getrennt werden. Das Material, von dem eine elektronenmikroskopische Oberflächenaufnahme abgebildet ist, quillt gut in organischen Lösungsmitteln. Die dabei auftretende Veränderung der Teilchengröße von $5-$ $8 \%$ beeinflußt die Wirksamkeit der Säule nicht. Sie kann wiederholt in Gradientenarbeitsweise mit mobilen Phasen aus Wasser und organischen Lösungsmitteln unter typischen Reversed-Phase Arbeitsbedingungen eingesetzt werden. Die Säulen können in einem weiten $\mathrm{pH}$-Bereich verwendet werden. Das Retentionsverhalten von 16 Proteinen mit stark 
unterschiedlichen $\mathrm{pI}$-Werten wird als Funktion vom $\mathrm{pH}$-Wert des Eluens untersucht. Gewöhnlich wird bei einer Säulentemperatur von $80^{\circ} \mathrm{C}$ gearbeitet. Analysenzeiten von $30 \mathrm{sec}$ bis $10 \mathrm{~min}$ reichen, um Proteingemische zu trennen. Die Lebensdauer der Säulen ist gut, sie wurden 3 Monate ohne Verlust ihrer Wirksamkeit eingesetzt. - J. Chromatogr. 445, 71 76 (1988). Dept. Chem. Engin., Yale Univ., New Haven, CT (USA)

R.H.S.

Trace determination and characterization of some proteins in blood serum by high-performance liquid chromatography with a time-resolved laser fluorimetric detector. J. Kawabata, K. Sauda, T. Imasaka and N. Ishibashi.

Verff. beschreiben eine Methode zur Charakterisierung und Bestimmung einiger Proteine (Globuline, Albumin), bei dem sie die HPLCTrennung unter Verwendung einer size-exclusion-Säule mit zeitaufgelöster, laserangeregter fluorimetrischer Detektion kombinieren. Das Gesamtsystem wird anhand einer schematischen Darstellung des Geräteaufbaus erläutert. Man erreicht mit dieser Methode eine Nachweisgrenze für Rinderserum-Albumin von 2,3 pMol. Der Wert ist abhängig von der Fluktuation der Untergrundfluorescenz des als Fluorophor benutzten freien 1-Anilin-8-naphthalinsulfonat (ANS). Die Mikropolarität der Bindungsstelle im Protein wird durch Messung der Fluorescenzdauer des an das Protein gebundenen ANS bestimmt. - Anal. Chim. Acta 208, 255-262 (1988). Fac. Engin., Kyushu Univ., Hakozaki, Fukuoka (J)

W. Czysz

Protein analysis on two-dimensional polyacrylamide gels in the femtogram range: Use of a new sulfur-labeling reagent. Y.V. Boxberg.

Ein ultraempfindliches Anfärbeverfahren für Proteinhomogenate, die durch zweidimensionale Polyacrylamidgelelektrophorese getrennt wurden, wird beschrieben. Die Proteine können nach Trennung auf ultradünnen Polyacrylamidschichten in der ersten Richtung mit einem neuen ${ }^{35} \mathrm{~S}$-Reagens markiert werden. Dann wird in der zweiten Richtung getrennt und mit Hilfe eines Röntgenfilms ausgewertet. Bei sehr langen Belichtungszeiten ist die Empfindlichkeit besser als die durch Silberanfärbung. Außerdem ist die quantitative Auswertung der geschwärzten Filme besser durchzuführen als die der mit Silber angefärbten Gele. Anal. Biochem. 169, 372-375 (1988). MPI Entwicklungsbiol., D-7400 Tübingen

R.H.S.

Potentiometric monitoring of proteins. Part IV. Application to electrophoresis gels. M.L. Hitchman, J.M. Fisher and F.W.M. Nyasulu.

A simple method for the determination of proteins separated by gel electrophoresis is described based on direct potentiometry with copper clectrodes. Results are presented for a number of proteins in agarose gels. Several different electrode designs are considered and the effects of various buffer systems are investigated. It is shown that cathodic pretreatment of the monitoring electrodes gives a fast and reproducible response which is sufficient to form the basis of a simple, reliable and inexpensive method for the quantitative monitoring of proteins in electrophoresis gels. - Analyst 113, 875-879 (1988). Dept. Pure Appl. Chem., Univ. Strathclyde, Glasgow (GB)

Application of Neuhoff's optimized Coomassie Brilliant Blue G-250/ammonium sulfate/phosphoric acid protein staining to ultrathin polyacrylamide gels on polyester films. $K$. Peisker.

An optimized Coomassie staining procedure, utilizing Coomassie Brilliant Blue G-250 in phosphoric acid/ammonium sulfate, was applied to ultrathin-layer isoelectric focusing in $0.18 \mathrm{~mm}$ polyacrylamide gels, and sodium dodecyl sulfate-polyacrylamide gel electrophoresis in 0.38 $\mathrm{mm}$ polyacrylamide gels, both backed to Gel-Fix polyester supporting films. After isoelectric focusing staining of gelatin and acidic proteins was better with the phosphoric acid/ammonium sulfate procedure than with conventional organic solvent methods. When applied to gels after sodium dodecyl sulfate-polyacrylamide gel electrophoresis the sensitivity of the phosphoric acid/ammonium sulfate method was equal to that on conventional staining but lower than on silver staining. - Electrophoresis 9, 236-238 (1988). St.-Elisabeth-Hosp., Halle (DDR)

A stain of iron-containing proteins sensitive to nanogramm levels of iron. C.-F. Kuo and I. Fridovich.
Ein neues Verfahren zur Anfärbung eisenhaltiger Proteine in Poly acrylamid-Elektropherogrammen wird beschrieben. Es beruht auf der katalytischen Wirkung des Eisens auf die Oxidation von Diaminobenzoesäure zu $\mathrm{H}_{2} \mathrm{O}_{2}$. Dazu werden die Gelelektropherogramme in $50 \mathrm{mM}$ Natriumacetat $(\mathrm{pH} 5,0)$ bei $35^{\circ} \mathrm{C}$ bewegt. $\mathrm{H}_{2} \mathrm{O}_{2}$, aus einer $30 \%$ igen Standardlösung, wird zu $40 \mathrm{mM}$ und Diaminobenzoesäuredihydrochlorid, aus einer 0,8 M Lösung, zu $80 \mathrm{mM}$ zugesetzt. Dann wird $30 \mathrm{~min}$ bei $35^{\circ} \mathrm{C}$ bewegt. Die Anfärbelösung wird dann dekantiert, die Gele zweimal mit Wasser gespült und in 7\%ige Essigsäure gestellt. Die Gele müssen lichtgeschützt aufbewahrt werden und innerhalb weniger Stunden abphotographiert werden. Banden mit bis hinunter zu $5 \mathrm{ng}$ an Protein gebundenen Eisen können mit diesem Verfahren sichtbar gemacht werden. - Anal. Biochem. 170, 183-185 (1988). Dept. Biochem., Duke Univ. Med. Center, Durham, NC (USA)

R.H.S.

Immunochemical determination of mouse and human IgG by adsorption on C-8 and C-18 columns. A.S. Attiyat and G.D. Christian.

Zur immunchemischen Bestimmung von Mäuse- und Human-IgG werden die Antigenlösungen direkt auf $\mathrm{C}_{18^{-}}$(Mäuse-IgG) bzw. $\mathrm{C}_{8^{-}}$ Säulen (Human-IgG) adsorbiert. Anschließend läßt man auf der Säule mit Meerrettich-Peroxidase-gebundenem Antikörper reagieren. Nach Waschen der Säule wird die katalytische Reaktion des Enzyms unter $\mathrm{H}_{2} \mathrm{O}_{2}$-Bildung wirksam. Das freigesetzte $\mathrm{H}_{2} \mathrm{O}_{2}$ reagiert mit Tetramethylbenzidin unter Bildung eines Farbstoffs, der im Eluat bei 455/452,5 nm photometrisch bestimmt wird. Die Eichkurven für Mäuse- und HumanIgG sind im analytischen Bereich linear. Die Nachweisgrenzen sind mit $1 \mu \mathrm{g}$ relativ hoch. Das wird als Folge der nicht optimierten Analysenbedingungen angesehen, und weil die Untergrundsignale hoch (aber reproduzierbar) sind. - Anal. Lett. 21, 827 - 833 (1988). Dept. Chem., BG10, State Univ., Seattle, WA (USA)

W. Czysz

Novel enzyme immunoassay (immune complex transfer enzyme immunoassay) for anti-insulin IgG in guinea pig serum. T. Kohno and E. Ishikawa.

Ein als Immunkomplex-Transfer-Enzymimmunoassay bezeichneter neuer Enzymimmunoassay (EIA) für Anti-Insulin-IgG in Meerschweinchen-Serum wird beschrieben. Das Anti-Insulin-IgG reagiert mit Dinitrophenyl-Rinderserum-Albumin/Insulin/Meerrettich-Peroxidase-Konjugat. Das Konjugat wird an affinitätsgereinigten Polystyrolkügelchen fixiert, die mit (Anti-Dinitrophenyl-Rinderserum-Albumin)-IgG vom Kaninchen präpariert wurden. Nach Eliminierung von nichtspezifischem Meerschweinchen-IgG-Testserum wird der Komplex von den Polystyrolkugeln mit Dinitrophenyl-L-Lysin eluiert und auf Polystyrolkugeln, die mit affinitätsgereinigtem (Anti-Meerschweinchen-IgG)IgG vom Kaninchen überzogen sind, übertragen. Die an diesen Kugeln fixierte Peroxidase-Aktivität ermöglicht die fluorimetrische Bestimmung. Die nach diesem Verfahren erreichten Nachweisgrenzen liegen $1000-$ 10000mal niedriger als bei der konventionellen EIA. - Anal. Lett. 21 , 1019 -1031 (1988). Dept. Chem., Med. Coll., Kiyotake, Miyazaki (J)

$$
\text { W. Czysz }
$$

Novel and ultrasensitive sandwich enzyme immunoassay (sandwich transfer enzyme immunoassay) for antigens. S. Hashida, K. Tanaka, T. Kohno and E. Ishikawa.

Verff. beschreiben einen neuen, ultrasensitiven Sandwich-Enzymimmunoassay (EIA) für Antigene. Sie führen dafür dje neue Bezeichnung "Sandwich-Transfer-EIA" ein. Man läßt Antigene mit Dinitrophenylmonoklonalen Antikörper-IgG $G_{1}$ der Maus mit Antikörper-Fab'- $\beta$-D galaktosidase-Konjugaten von Kaninchen reagieren. Der gebildete Komplex wird an affinitätsgereinigten Polystyrolperlen fixiert, die vorher mit (Anti-Dinitrophenyl-Rinderserumalbumin)-IgG belegt wurden Die weitere Behandlung entspricht der vorstehend referierten Methodik für Anti-Insulin.IgG in Meerschweinchen mit dem Unterschied, daß $\beta$ D-Galaktosedase-Aktivität an den Polystyrolperlen gebunden und für die fluorimetrische Endbestimmung benutzt wird. Zum Schluß werden Beispiele der Bestimmung von menschlichem Rhyrois-stimulierendem Hormon und von menschlichem Wachstumshormon beschrieben. Anal. Lett. 21, $1141-1154$ (1988). Dept. Biochem., Med. Coll., Kiyotake, Miyazaki (J)

W. Czysz

A quantitative extraction method for conjugated bile acids from human serum using reversed-phase octadecyl bonded silica cartridges for HPLC analysis. Y.Y. Zhang, W. Swobodnik, P. Fürst and H. Ditschuneit. 
Konjugierte Gallensäuren aus dem Serum können nach einem Extraktionsschritt und nach Alkalisierung der Probe mittels RP-C-18-Patronen isoliert werden und so selektiv der quantitativen Bestimmung zugeführt werden. Die Alkalisierung ist notwendig, um die Gallensäuren von Albumin zu trennen. Dies führt jedoch gleichzeitig zu einer verkürzten Lebensdauer der gebundenen Phase. - Chromatographia 25, 545-546 (1988). Dept. Internal. Med., Univ. Clin., U1m (D) M.J. Rittich

Electrochemical oxidation of bilirubin and biliverdin in dimethyl sulfoxide. F. Moussa, G. Kanoute, C. Herrenknecht, P. Levillain and F. Trivin.

The mechanism of the electrochemical oxidation of bilirubin was reexamined to explain the differences in behavior reported in previous studies published by various authors. The findings point to an ECEC mechanism. Only the first step of this mechanism is specific to bilirubin, and it may consequently be used as a criterion of purity for this molecule. - Anal. Chem. 60, 1179-1185 (1988). Lab. Biochim. Appl., Cent. Etud. Pharm. Paris-Sud, Chatenay-Malabry (F)

Determination of pheophytinatonickel(II) by reversed-phase high-performance liquid chromatography. K. Furuya, N. Ohki, H. Inoue and T. Shirai.

HPLC determination of pheophytinatonickel(II) (PheoNi) prepared by the replacement of magnesium(II) in chlorophyll with nickel(II) is described. The good separation of PheoNi was obtained by using chemically bonded $\mathrm{C}_{18}$ as the stationary phase and acetone/methanol (50:50) as the mobile phase. Conventional spectrophotometric method was also used for the determination of PheoNi. For the synthetic samples prepared by mixing (pheophytinato a) nickel(II) [(Pheo-a) Ni] and (pheophytinato b) nickel(II) [(Pheo-b)Ni], analytical values obtained by the spectrophotometric method were very high compared to those obtained by HPLC. In the proposed HPLC method, (Pheo-a)Ni and (Pheo-b)Ni could be determined in the concentration range of $0.028-30 \mu \mathrm{g} / \mathrm{ml}$ and $0.038-30 \mu \mathrm{g} / \mathrm{ml}$ with relative standard deviations $(\mathrm{n}=10)$ of $3.1 \%$ and $0.8 \%$, respectively. - Chromatographia 25, 319-323 (1988). Dept. Appl. Chem., Fac. Sci. Technol., Keio Univ., Hiyoshi, Yokohama (J)

Detection of non-typical porphyrin isomers in human urines by ion-pair reversed-phase high-performance liquid chromatography. K. Jacob, I. Kossien, E. Egeler and M. Knedel.

Ein verbessertes Ionenpaar-HPLC-Verfahren zur Trennung der Uroporphyrinisomeren I, II und III wird beschrieben. Die Isomeren III und IV werden nicht aufgetrennt. Isokratisch können die Uroporphyrine I, II und III + IV auf einer LiChrosorb RP-18 Säule mit wäßriger Phosphatpufferlösung ( $\mathrm{pH}$ 5) getrennt werden. Die Coprophorphyrinisomeren werden isokratisch in einem System 54\% Phosphatpuffer $(\mathrm{pH} \mathrm{6,6)} \mathrm{und}$ $46 \%$ Methanol/Acetonitril/Wasser $(72: 21: 7)$ unter Zusatz von 8,9 mmol/1 Tetrabutylammoniumphosphat $(\mathrm{pH} 7,4)$ getrennt. Die klinische Bedeutung der einzelnen untypischen Porphyrinisomeren wird erläutert. - J. Chromatogr. 441, 171-181 (1988). Inst. Klin. Chem., Klinikum Großhadern, Univ., München (D)

R.H.S.

Use of a discrete diode array spectrophotometer for the quantitative and qualitative analysis of cytochrome P-450. L.W. Whitehouse and C.J. Paul.

Cytochrome P-450, the hemoprotein located in the endoplasmic reticulum of mammalian cells and responsible for the metabolism of xenobiotics, was qualitatively and quantitatively analyzed using the HP$8450 \mathrm{~A}$ diode array spectrophotometer. The diode array instrument was compared to a conventional spectrophotometer and the advantages of the diode array instrument over conventional spectrophotometry with respect to the analysis of cytrochrome P-450 were discussed. Mikrochin. Acta 1987,II, 65-72. Biochem. Toxicol,, Toxicol. Div., Bureau Drug Res., Ottawa (CDN)

Selective determination of guanine and its nucleosides and nucleotides by reaction with phenylglyoxal as a fluorogenic reagent. $M$. Kai, Y. Ohkura, S. Yonekura and M. Iwasaki.

Zur Bestimmung von Guanin und den davon abgeleiteten Nucleosiden und Nucleotiden wird ein fluorimetrisches Verfahren ausgearbeitet. Grundlage ist die Reaktion dieser Verbindungen mit dem fluorogenen Reagens Phenylglyoxal in schwach saurer Lösung (pH 4,0). Anregung bei $365 \mathrm{~nm}$, Emissionsmessung bei $510 \mathrm{~nm}$. Die Untersuchungen zeigen, daß andere Nucleinsäurebasen wie Adenin, Cytosin, Uracil und Thymin sowie auch deren Nucleoside und Nucleotide unter den vorgeschlagenen Bedingungen keine störende Fluorescenz erzeugen. Das Verfahren ist sehr empfindlich (Nachweisgrenzen im Reaktionsgemisch zwischen 47 und 310 pmol) und selektiv für Guanin und seine Derivate. - Anal Chim. Acta 207, 243-249 (1988). Fac. Pharm. Sci, Kyushu Univ., Fukuoka (J)

W. Czysz

Single-step high-performance liquid chromatographic analysis of nucleoside monophosphate for ribonuclease specificity. S. Abel, G.-J. Krauss and $\mathrm{K}$. Glund.

Ein Reversed-Phase HPLC-Verfahren, welches die Messung der Bildung von $2^{\prime}: 3^{\prime}$-cyclischen Nucleosidmonophosphaten und $2^{\prime}\left(3^{\prime}\right)-\mathrm{Nu}-$ cleosidmonophosphaten während der enzymatischen Hydrolyse von $\mathrm{He}$ fe-RNA gestattet, wird beschrieben. Dazu werden Proben des Inkubationsgemisches auf einer Octadecyl-Silica 100 Polyol $(10 \mu \mathrm{m})$-Säule isokratisch mit $0,02 \mathrm{M} \mathrm{NH}_{4} \mathrm{H}_{2} \mathrm{PO}_{4}(\mathrm{pH}$ 6.2) als mobiler Phase analysiert. Der Nachweis wird im UV bei $254 \mathrm{~nm}$ durchgeführt. Die Retentionszeiten der Ribonucleosidmonophosphate werden mitgeteilt. - J. Chromatogr. 446, 187-189 (1988). Sekt. Biowissenschaften, Pflanzenbiochem. Abt. Neuwerk I, Martin-Luther-Univ., Halle (DDR) R.H.S.

Evidence for a radical intermediate in the anodic oxidation of reduced nicotinamide adenine dinucleotides obtained by electrogenerated chemiluminescence. J. Ludvík and J. Volke.

Mit Hilfe elektrisch erzeugter Chemiluminescenz wird gezeigt, daß bei der Elektrooxidation von NADH und NADPH an einer Pt-Anode in wasserfreiem oder bis $15 \%$ Wasser enthaltenden Dimethylsulfoxid die Radikale NAD' und NADP* als Zwischenprodukte auftreten. Dabei scheint ein ECE-Mechanismus (R.L. Blankespoor and L.L. Miller: J. Electroanal. Chem. 171, 231 (1984)) zu dominieren. Die Vorteile der Verwendung von Dimethylsulfoxid zur Beobachtung des Phänomens werden herausgestellt. - Anal. Chim. Acta 209, 69-78 (1988). J. Heyrovský Inst. Phys. Chem. Electrochem., CS Acad. Sci., Prag 8 (CS)

$$
\text { W. Czysz }
$$

New reversed-phase high-performance liquid chromatographic column for oligonucleotide separation. H. Moriyama and Y. Kato.

Das chromatographische Reversed-Phase Material TSKgel OligoDNA RP besitzt eine große Porengröße und Octadecylgruppen, die an Silicagel gebunden sind. Es ist für die Trennung mittelmolekulargewichtiger Verbindungen wie Oligo- und Polynucleotiden geeignet. Die Trennungen werden mit linearen Gradienten zwischen 5 und $25 \%$ organischem Lösungsmittel in $0.1 \mathrm{M}$ Ammoniumacetat $(\mathrm{pH} 7,0)$ durchgeführt. Als organische Lösungsmittel werden Methanol, Acetonitril und Isopropanol getestet. Der Nachweis wird bei $260 \mathrm{~nm}$ im UV durchgeführt. Die erhaltenen Ergebnisse werden mit solchen verglichen, die auf TSKgel ODS-80TM-Säulen erhalten wurden. - J. Chromatogr. 445, 225-233 (1988). Centr. Res. Lab., Tosoh Corp., Shinnanyo, Yamaguchi (J) R.H.S.

Enhancing the sensitivity of DNA detection and recovery from agarose gels. F. Georges, S. Girard, R.N. Chibbar and F. Constabel.

By inserting nitrocellulose strips into agarose gels alongside the electrophoresed lanes and passing an electric current perpendicularly in the direction of the strips, highly efficient transfer of DNA bands onto the membrane in the form of concentrated dots is achieved. DNA detection limis by this technique are enhanced, at least three times as visualized by ethidium bromide fluorescence and at least twice more by radiolabeling. - Electrophoresis 9, $213-216$ (1988). Plant Biotechnol. Inst., Nat. Res. Council of Canada, Saskatoon, Saskatchewan (CDN)

Fluorometric analysis of DNA in cell cultures. $\mathrm{K}$. Janakidevi, C.D. Murray, C. Sell and P. Held.

Ein einfaches, reproduzierbares Fluorescenzverfahren zur Bestimmung von Mikrogramm- und Submikrogramm-Mengen an DNA wird beschrieben. Zur Bestimmung werden die Zellkulturmedien mit $0,5 \mathrm{~N}$ $\mathrm{HClO}_{4}$ zentrifugiert und die Lipide durch Extraktion mit Ethanol/Ether (3:1) entfernt. DNA wird mit $0,5 \mathrm{~N} \mathrm{HClO}_{4}$ durch 125 min Erhitzen auf $70^{\circ} \mathrm{C}$ hydrolysiert und die Hydrolysate mit Diaminobenzoesäurechlorid versetzt. Nach $2 \mathrm{~h}$ Stehen bei Zimmertemperatur wird die Fluorescenz 
bei $410 / 505 \mathrm{~nm}$ gemessen. Das Verfahren ist besonders geeignet für die Bestimmung von Zellzyklen und Zellwachstum unter Verwendung von $\left[{ }^{3} \mathrm{H}\right]$ Thymidin als radioaktivem Tracer, - Anal. Biochem. 172, 78 - 81 (1988). Dept. Pathol., Neil Hellman Building, Albany Med. Coll., Albany, NY (USA)

R.H.S.

High-performance liquid chromatographic determination of lombricine and $\mathrm{N}$-phosphoryl lombricine in the earthworm by precolumn fluorescence derivatisation with o-phthalaldehyde-ethanethiol. M.R. Euerby, L.Z. Partridge and W.A. Gibbons.

2-Guanidinoethyl-2-amino-2-carboxyethylhydrogenphosphat (Lombricin) und N-Phosphoryllombricin können aus biologischen Extrakten der Würmer Allolobophora caliginosa, Octolasium cyaneum und Lumbricus terrestris nach Derivatisierung mit o-Phthalaldehyd in methanolischem Boratpuffer ( $\mathrm{pH}$ 9.5) unter Zusatz von Ethanthiol durch HPLC auf einer Spherisorb ODS II-Säule unter Vorschaltung einer CO:Pell ODS-Schutzsäule analysiert werden. Es wird mit einem stufenweisen Gradienten zwischen 0.3 $\mathrm{M} \mathrm{NaH}_{2} \mathrm{PO}_{4}$-Puffer $(\mathrm{pH} 7,2) /$ Tetrahydrofuran/ Wasser $(100: 25: 1875)$ und $0.3 \mathrm{M} \mathrm{NaH}_{2} \mathrm{PO}_{4}$-Puffer $(\mathrm{pH} 7.2) /$ Acetonitril/ Wasser $(45: 1100: 855)$ als mobilen Phasen gearbeitet. Der fluorimetrische Nachweis wird bei $344 / 443 \mathrm{~nm}$ durchgeführt. Im Bereich von $20-$ 80 pmol pro Injektion erhält man für Lombricin eine lineare Eichkurve, die Nachweisgrenze liegt im unteren Femtomol-Bereich. Das Verfahren wird außer für Lombricin und sein säurelabiles N-Phosphorylderivat auch für andere saure Aminosäuren und ihre $\mathrm{O}$ - und $\mathrm{N}$-phosphorylierten Derivate empfohlen. - J. Chromatogr. 445, 433-440 (1988). Dept Pharm. Chem. School Pharm., Univ., London WC1N (GB) R.H.S.

A new chromogenic substrate for assay and detection of $\boldsymbol{\alpha}$-amylase. $P$. Biely, D. Mislovičová, O. Marković and V. Kaláč.

Ein neues lösliches chromogenes Substrat für $\alpha$-Amylase wird durch Kopplung partiell hydrolysierter Stärke mit dem Farbstoff Ostazin Brilliant Rot H-3B hergestellt. Das Substrat kann aus gepufferten Lösungen mit Ethanol gefällt werden und ist sowohl für die Bestimmung von $\alpha$ Amylase als auch zur Detektion von Amylaseisoenzymen in Gelen und zur Selektion von mikrobischen Produzenten des Enzyms geeignet. Anal. Biochem. 172, 176-179 (1988). Inst. Chem., Centre Chem. Res., Slovak Acad. Sci, Bratislava (CS)

R.H.S.

A radiochemical microassay for asparate aminotransferase activity in the nervous system. D. Garrison, J. Beattie and M.A.A. Namboodiri.

Ein radiochemisches Verfahren zur Bestimmung der Aktivität von Aminotransferase im Nervensystem wird beschrieben. Das Verfahren beruht auf dem Austausch von Tritiumatomen an den Stellungen 2 und 3 von $\mathrm{L}-2,3-\left[{ }^{3} \mathrm{H}\right]$ Asparat mit Wasser bei der Transaminierung dieser Aminosäure in Gegenwart von $\alpha$-Ketoglutarat unter Bildung von Oxaloacetat. Das mit Tritium markierte Wasser wird von dem markierten Asparat über einer Kationenaustauscher-Säule abgetrennt. Bis zu 120 min erhält man eine lineare Produktbildung. Es wird mit Gewebeproben von 0,5-10 $\mu$ g gearbeitet. - Anal. Biochem. 172, 96-103 (1988), Dept. Biol., Georgetown Univ., Washington, DC (USA) R.H.S.

Fluorometric continuous kinetic assay of $\alpha$-chymotrypsin using new protease substrates possessing long-wave excitation and emission maxima. J.H. Baustert, O.S. Wolfbeis, R. Moser and E. Koller.

Ein direktes und kontinuierliches kinetisches Verfahren zur fluorimetrischen Bestimmung von $\alpha$-Chymotrypsin wird beschrieben. Dabei wird 2-Aminoacridon (2-AA) als neuer Fluorophor in der analytischen Biochemie eingeführt. N-Succinyl- und N-Glutaryl-Phenylalanin können über eine Peptidbindung an 2-AA gekoppelt werden und das resultierende fluorogene Substrat kann durch die zwei Enzyme gespalten werden. Da Substrat und Hydrolyseprodukt stark unterschiedliche spektrale Eigenschaften aufweisen, ist die Zunahme der langwelligen Fluorescenz von 2-AA (bei $450 / 570 \mathrm{~nm}$ ) ein Maß für die Enzymaktivität. Die kinetischen Parameter für die Hydrolyse von verschiedenen fluorogenen Substraten durch $\alpha$-Chymotrypsin bei $25^{\circ} \mathrm{C}$ werden miteinander verglichen. Das neue fluorogene Substrat weist nahezu ideale kinetische Eigenschaften zur Bestimmung imodolytischer Aktivitäten von Peptidasen auf. Durch die spektralen Eigenschaften des 2-AA können Messungen in langwelligen Bereichen durchgeführt werden, in denen keine starke Untergrundfluorescenz durch biologische Materialien zu erwarten ist. -
Anal. Biochem. 171, 393-397 (1988). Anal. Div., Inst. Organ. Chem., Karl Franzens Univ., Graz (A) R.H.S.

Electrostatic features of molecular recognition by cyclic urea mimics of chymotrypsin. C.A. Venanzi and K. Namboodiri.

Das elektrostatische Potentialmuster eines Moleküls wurde zur Untersuchung der elektrostatischen Eigenschaften der Molekülstruktur von zwei cyclischen harnstoffartigen Gebilden an der aktiven Position von $\alpha$-Chymotrypsin benutzt. Man erhielt diese Strukturen über die Molekülmechanik der räumlichen Potentialenergie-Oberfläche der Moleküle. Unter Verwendung von zwei verschiedenen Atompunkt-Ladungssets wurden Berechnungen angestellt, um die Wirkung der Ladung auf das elektrostatische Potentialmuster abzuschätzen. Die Wahl der Atompunktladung beeinflußt das Wasserstoffbindungsmuster der Hydroxylund Imidazol-Abschnitte des Moleküls und führt zu Unterschieden in der räumlichen Orientierung der elektrostatischen Potential-Minima. - Anal. Chim. Acta 210,151-162 (1988). Dept. Chem. Engin. and Chem., Inst. Technol., Newark, NJ (USA) W. Czysz

Continuous-flow potentiometric determination of horseradish peroxidase with a fluoride-selective electrode. P.W. Alexander and C. Maitra.

Für die Bestimmung von Meerrettich-Peroxidase (MRP) wird ein kontinuierliches Durchflußverfahren mit potentiometrischer Bestimmung an einer Fluorid-selektiven Elektrode ausgearbeitet. Die Reaktionsbedingungen für die durch MRP katalysierte Oxidation von pFluoranilin $(0,104 \mathrm{M})$ mit $\mathrm{H}_{2} \mathrm{O}_{2}(4,0 \mathrm{mM})$ als Oxidans in einem $0,16 \mathrm{M}$ Acetatpuffer bei $\mathrm{pH} 4,6$ werden ausgearbeitet. Mit dieser Methode kann MRP im Konzentrationsbereich $0,016-0,12 \mathrm{E} / \mathrm{ml}$ bei einer Durchsatzrate von 24 Probenaliquots/h bestimmt werden. Das Ausmaß der Störungen durch MRP inhibierende Substanzen, einschließlich Metallionen, Cyanid und Sulfid, wird für den MRP-Konzentrationsbereich $1 \mu \mathrm{M}$ $1 \mathrm{MM}$ bestimmt. Das Verfahren wird bei der Analyse von Rübensaft und Milch eingesetzt. - Anal. Chim. Acta 208,173 - 181 (1988). School Chem., Univ. N.S.W., Kensington, NSW (AUS) W. Czysz

Activity staining of inulin fructotransferase II on polyacrylamide gels. R.H.F. Beck and T. Uchiyama

Fructotransferasen II sind Enzyme, die nichtrefuzierende Difructoseanhydride aus Fructanen produzieren. Zur Anfärbung der Aktivität dieser Enzyme auf Gelelektropherogrammen wird auf Polyacrylamidgelen mit einem Tri(hydroxymethyl)aminomethan/Glycin-Puffer $2 \mathrm{~h}$ bei $300 \mathrm{~V}$ getrennt. Dann wird der Puffer mit Wasser ausgewaschen und die Gele in $0.1 \mathrm{M}$ Acetatpuffer (pH 5) geschwenkt. Dann wird über Nacht in Methanol/Essigsäure/Wasser (5:1:5) in einem Kühlschrank aufbewahrt. Man erhält transparente Banden auf den opalescierenden Gelen. - J. Chromatogr. 445, $282-284$ (1988). Univ. Bodenkultur, Inst. Chem., Arbeitsgruppe Lebensmittel-, Umwelt und Naturstoffchem., Wien (A)

R.H.S.

Thin-layer agarose isoelectric focusing of alkaline phosphatase isoenzymes from human neutrophils. A. Brisson-Lougarre, H. Vergnes, J. Grozdea and R. Biermé.

An improved method for thin-layer agarose isoelectric focusing of alkaline phosphatase (AP) from human neutrophils is described. The solubilization of AP isoenzymes was studied with four detergents. The best results were obtained after sonication with Zwittergent 3-12 $11 \%$ final concentration), followed by butanol extraction and ultracentrifugation $105000 \times g$ for $1 \mathrm{~h}$. The cytosol can be stored at $0^{\circ} \mathrm{C}$ or $-80^{\circ} \mathrm{C}$, but not at $-20^{\circ} \mathrm{C}$. Dialysis of the cytosol against a Tris buffer, $\mathrm{pH} 7.5$, was imperative prior to focusing for removal of the detergent. Enzyme visualization is enhanced by incorporation of $\mathrm{ZnCl}_{2}(3 \mathrm{mM})$ into the agarose gel. The focusing patterns consist of two sets of isoenzymes: two main zones with $\mathrm{p} I 6.4$ and 6.8 and minor components with $\mathrm{p} I 4.2,4.8$ and 5.2. - Electrophoresis 9, $221-224$ (1988). Serv. Univ. Hématol. Fac. Méd. Toulouse, CNRS-INSERM, Rangueil (F)

Simple assay procedure for tyrosine hydroxylase activity by high-performance liquid chromatography employing coulometric detection with minimal sample preparation. M. Naoi, T. Takahashi and T. Nagatsu.

Ein einfaches Verfahren zur Bestimmung der Aktivität von 'Tyrosinhydroxylaseaktivität in rohen Gewebeproben wird beschrieben, welches 
nur geringe Probenvorbereitungen verlangt. Nach Inkubation der Enzymproben mit L-Tyrosin und einem Tetrahydropterin-Cofaktor in Abwesenheit oder in Gegenwart des Inhibitors für aromatische L-Aminodecarboxylase p-Brombenzyloxyamin wird die Reaktion mit $0,1 \mathrm{M} \mathrm{HClO}_{4}$ unterbrochen. Nach Zentrifugation wird filtriert und direkt auf einer Cosmosil $\mathrm{C}_{18}$-Säule unter Vorschaltung einer analogen Schutzsäule mit $90 \mathrm{mM}$ Natriumacetat, $35 \mathrm{mM}$ Zitronensäure, $130 \mu \mathrm{M} \mathrm{Na}{ }_{2}$ EDTA und $230 \mu \mathrm{M}$ Natriumoctansulfonat $+10,5 \%$ Methanol chromatographiert. Der Nachweis erfolgt mit einem Coulochem elektrochemischen Detektor. Die Reaktionsbedingungen zur Bestimmung der Tyrosinhydroxylaseaktivität in Hirnhomogenaten und PC12h-Zellen werden mit diesem Verfahren untersucht. - J. Chromatogr. 427, 229 - 238 (1988). Dept. Biochem., Univ. School Med., Nagoya (J) R.H.S.

Quantitation of R-836, a new oral bronchodilator, by high-performance liquid chromatography using manual or robotic sample preparation. T.M. Welscher, K.E. Armstrong, K.A. Rhode, A.M. Miller, J.H. Sandahl and S.F. Chang.

A simple and selective HPLC method has been developed for the quantitation of R-836 (an investigational oral bronchodilator) in human plasma and urine, dog plasma and urine, and rat plasma. The method consists of reversed-phase HPLC with UV detection. Sample preparation involved a one-step protein precipitation procedure and was performed both manually and by a Zymate robotic system. Precision and accuracy results showed excellent reproducibility; results using the robotic procedure were slightly better than the manual procedure. The robotic procedure was capable of preparing the samples with minimal operator handling. - J. Liquid Chromatogr. 11, 435-445 (1988). Drug Metabol. Dept., Riker Labs. Inc., Subsid. 3M, Saint Paul, MN (USA)

Analysis of a new $\mathrm{H}_{2}$ receptor antagonist, 3-amino-5-[3-[4-(1-piperidinoindanyloxy)|propylamino|-1-methyl-1H-1,2,4-triazole (I), in human plasma and urine by high-performance liquid chromatography. J.R. Miksic, E.R. Rivel and K. Rush.

Ein HPLC-Verfahren zur Bestimmung des neuen Histamin $\mathrm{H}_{2}$-Rezeptorantagonisten I in Humanplasma und Urin wird beschrieben. Dazu werden die mit internem Standard versetzten alkalischen Plasmaproben mit Ethylacetat extrahiert, dann wird in $0,01 \mathrm{M} \mathrm{HCl}$ rückextrahiert und die saure Phase genau wie direkt mit Wasser und internem Standard versetzte Urinproben auf einer Alkylphenyl-gebundenen Säule mit einem Gemisch aus 0,02 M Natriumphosphat (pH 3,0)/Methanol/Acetonitril $(60: 16: 24$ für Plasma und $60: 20: 20$ für Urin) analysiert. Das Effluat wird bei $214 \mathrm{~nm}$ ausgewertet. Die untere Nachweisgrenze wird mit 10 $\mathrm{ng} / \mathrm{ml}$ für Plasma und mit $1 \mu \mathrm{g} / \mathrm{ml}$ für Urin angegeben. Die Variationskoeffizienten liegen unter 10\%, - J. Chromatogr. 428, 113-121 (1988). Rorer Centr. Res., Horsham, PA (USA)

R.H.S.

Determination of flurbiprofen in dosage form and in biological fluids by high-performance liquid chromatography. S.A. Babhair.

A HPLC method using fluorescence detection is described. The method for dosage forms involves grinding of a $100 \mathrm{mg}$ tablet, suspension in methanol, filtration and adjusting to the appropriate concentration and $10 \mu \mathrm{l}$ is injected onto the column. In the case of biological fluids a series of standard solutions were prepared in $0.1 \mathrm{~N}$ sodium hydroxide and a known amount was added to $1 \mathrm{ml}$ of serum or urine which was then acidified, extracted with ethylacetate, evaporated and the residue was then dissolved in a known volume of the mobile phase. Complete separation of the drug was achieved in about 6.5 minutes under the used conditions. - J. Liquid Chromatogr. 11, $463-473$ (1988). Dept. Pharmceut., Coll. Pharm., King Saud Univ., Riyadh (Saudi Arabia)

Simple high-performance liquid chromatographic method for the measurement of amiloride in body fluids. G. Forrest, G.T. McInnes, A.P. Fairhead, G.G. Thompson and M.J. Brodie.

Ein vereinfachtes schnelles HPLC-Verfahren zur Bestimmung des Kalium-sparenden Agens Amilorid in Plasma und Urin wird beschrieben.
Ein schnelles, sauberes und einfaches Aufarbeitungsverfahren erhält man, wenn man nach Zusatz von internem Standard die Proben über eine BondElut $\mathrm{C}_{8}$-Säule extrahiert. Die Elution erfolgt mit $50 \%$ mobiler Phase, $45 \%$ Methanol und 5\% Eisessig. 10 Proben können in weniger als 5 min bearbeitet werden. Die HPLC erfolgt dann auf einer $\mathrm{C}_{18}$-Säule mit $14 \%$ Acetonitril $+4 \mathrm{ml}$ Eisessig/1 ( $\mathrm{pH} 4,5$ mit Triethylamin). Der Nachweis wird im UV bei $365 \mathrm{~nm}$ durchgeführt. Im Bereich von 1-50 $\mathrm{ng} / \mathrm{ml}$ erhält man Wiederfindungsraten von $100,9 \%$ mit Variationskoeffizienten von 4,6\%. - J. Chromatogr. 428, $123-130$ (1988). Univ. Dept. Med., Gardiner Inst., Glasgow (GB) R.H.S.

Determination of eproxindine hydrochloride in human plasma by capillary gas chromatography. W. Dahmen, W. Gielsdorf, B. Jeremic, G. Achtert and H.-J. Hausleiter.

Ein empfindliches und selektives Verfahren zur Bestimmung des antiarrhythmisch wirkenden Eproxindinhydrochlorids in Plasma wird beschrieben. Dazu wird die ammoniakalische Humanplasmaprobe über eine Extrelutsäule gegeben, die mit Diethylether extrahiert wird. Der Rückstand des eingedampften Eluats wird in Ethanol aufgenommen und gaschromatographisch auf einer mit Methylsilicon beschichteten Capillarsäule mit einem Temperaturprogramm von $270-300^{\circ} \mathrm{C}$ analysiert. Der Nachweis wird mit einem Stickstoff-Phosphor-Detektor durchgeführt. Im Bereich von $10-1000 \mathrm{ng} / \mathrm{ml}$ in Plasma erhält man eine lineare Eichkurve, $10 \mathrm{ng} / \mathrm{ml}$ wird als Nachweisgrenze angesehen. Im Bereich von $1000 \mathrm{ng} / \mathrm{ml}$ liegt die Wiederfindensrate bei $80 \%$. - J. Chromatogr. 427, 157-161 (1988). Dept. Biochem., Kali Chemie AG, Sparte Pharma, D-3000 Hannover

R.H.S.

Rapid and inexpensive high-performance liquid chromatographic method for the quantification of flecainide in serum. B.K. Krämer, F. Mayer, H.M. Liebich, K.M. Ress, V. Kühlkamp, J.U. Becker, T. Risler and L. Seipel.

Das zur Behandlung von Rhythmusstörungen eingesetzte Flecainidacetat kann mit Hilfe eines HPLC-Verfahrens schnell und billig aus Serumproben bestimmt werden. Dazu werden die Serumproben mit pChlordisopyramid in $0,01 \mathrm{M} \mathrm{HCl}$ als internem Standard, $1 \mathrm{M} \mathrm{NaOH}$ und Dichlormethan zentrifugiert. Der Rückstand der eingedampften organischen Phase wird in $0,01 \mathrm{M} \mathrm{HCl}$ aufgenommen und auf einer ODS Reversed-Phase Säule mit $45 \%$ Acetonitril in einem Gemisch aus $994 \mathrm{ml}$ Wasser, $5 \mathrm{ml}$ PIC B-8 Reagens und $1 \mathrm{ml}$ Triethylamin chromatographiert. Das Säuleneffluat wird bei $222 \mathrm{~nm}$ im UV ausgewertet. Im gesamten untersuchten Konzentrationsbereich wird eine lineare Eichkurve erhalten. Die Wiederfindensraten betragen $99,5 \pm 2,3 \%$ für Flecainid und 102,7 $\pm 3,4 \%$ für den internen Standard. Die untere Nachweisgrenze liegt bei $0,05 \mu \mathrm{g} / \mathrm{ml}$. - J. Chromatogr. 427, 351 - 358 (1988). Med. Univ. Klinik, D-7400 Tübingen

R.H.S.

Simultaneous determination of clomipramine and its N-desmethyl metabolite in human whole blood by capillary gas chromatography with massselective detection. A. Sioufi, F. Pommier and J.P. Dubois.

Ein Verfahren zur gleichzeitigen Bestimmung von Clomipramin, einem tricyclischen Antidepressivum, und seinem N-Desmethylmetaboliten bis hinunter zu Konzentrationen von $2 \mathrm{nmol} / \mathrm{l}$ in Humanblut wird beschrieben. Nach Zusatz einer bekannten Menge von ${ }^{2} \mathrm{H}$-markiertem internen Standard werden die Verbindungen in n-Heptan/Isoamylalkohol $(99: 1)$ bei basischen pH-Werten extrahiert, dann in saure wäßrige Lösung rückextrahiert und bei basischen $\mathrm{pH}$-Werten erneut in $\mathrm{n}$-Heptan extrahiert. N-Desmethylclomipramin und der interne Standard werden mit Pentafluoropropionanhydrid derivatisiert. Die Derivate werden auf einer $12,5 \times 0,2 \mathrm{~mm}$ Quarzcapillarsäule mit Methylsiliconbeschichtung mit einem Temperaturprogramm von $200-280^{\circ} \mathrm{C}$ analysiert. Der Nachweis wird mit einem massenselektiven Detektor durchgeführt. Die Nachweisgrenze wird mit $1 \mathrm{ng} / \mathrm{ml}$ für Clomipramin und N-Desmethylclomipramin angegeben, niedrigere Konzentrationen haben einen Variationskoeffizienten über 13\%. - J. Chromatogr. 428, 71 - 80 (1988). Lab. Ciba-Geigy, Biopharm. Res. Centre, Rueil-Malmaison (F) R.H.S. 